Electrochimica Acta, 2003, Volume 48, Issue 9, Pages 1193-1210.

ISSN: 0013-4686

DOI: $10.1016 / \mathrm{S} 0013-4686(02) 00828-9$

(C) 2003 Elsevier Science Ltd. All rights reserved.

http://www.sciencedirect.com/science/article/B6TG0-47TWXK6-5/2/6578b9e305630eb8703b80b216e7e58f

http://www.elsevier.com/wps/find/journaldescription.cws_home/205/description\#description

\title{
Transitions between pitting and intergranular corrosion in AA2024
}

\author{
Weilong Zhang, G.S. Frankel
}

Fontana Corrosion Center, Department of Materials Science and Engineering, The Ohio State University

\begin{abstract}
The pitting and intergranular corrosion (IGC) behavior of various tempers of AA2024 was investigated in 1 $\mathrm{M} \mathrm{NaCl}$. The breakdown potentials associated with pitting or IGC were determined. The breakdown potentials were found to be almost independent of sample orientation for any given temper. Artificial aging had a strong effect on polarization behavior and localized corrosion morphology. The anodic polarization curves of AA2024 in the solution heat treated and water-quenched condition, T3, and T3+ tempers exhibited two breakdown potentials, whereas overaged AA2024-T8, T8+, and solutionized and furnace cooled AA2024 exhibited only one breakdown potential. When two breakdown potentials were observed, the more active one was found to be related to the transient dissolution of $\mathrm{S}$ phase $\mathrm{Al}_{2} \mathrm{CuMg}$ particles leading to pitting while the noble one was thought to result primarily from initiation and growth of IGC. The breakdown potentials decreased with increasing aging time at $190^{\circ} \mathrm{C}$, and only one breakdown potential was measured for T8 and T8+ tempers. Unlike the T3 temper, no sharp IGC was found for these tempers. Selected granular attack from breakdown of the copper-depleted matrix was believed to be the cause for localized corrosion in the T8 and T8+ tempers. The effect of nitrate and sulfate ions on the localized corrosion behavior was also studied.
\end{abstract}

\section{Introduction}

Pitting and intergranular attack, including exfoliation, are two common forms of localized corrosion in high strength Al alloys such as AA2024-T3 in chloride-containing aqueous environments. Pits and intergranular corrosion (IGC) can be potential sites for initiation of cracks, resulting in catastrophic failure by stress corrosion cracking or corrosion fatigue. A mechanistic understanding of pitting and IGC susceptibility in Al alloys and quantification of their growth kinetics, therefore, are of scientific interest and technological importance.

The problem of pitting and IGC susceptibility in high strength Al alloys has been studied for many years. In principle, both pitting and IGC result from a local breakdown of the passive film that forms on the surface, but the exact mechanism of the breakdown is still not clear. Attack that occurs at intermetallic particles, or in the matrix of a grain is called pitting, whereas attack restricted to grain boundary (GB) regions is called IGC. From an electrochemical point of view, both pitting and IGC processes seem to be very similar in nature. For example, chloride ions have been reported to be necessary for both pitting and IGC in Al alloys [1]. The growth of pits and IGC is believed to depend on potential [2]. As pits grow into the microstructure, they can develop into IGC or exfoliation (a form of IGC found in wrought Al alloys), which can penetrate deeply into the microstructure [3,4]. To some extent, IGC can be regarded as a special kind of pitting corrosion occurring preferentially at the grain boundaries for Al alloys since the mechanism of IGC was found to be of the same nature as the process of pitting [1,2,5-8]. However, differences clearly exist between pitting and IGC. For example, artificial aging is thought to minimize IGC susceptibility, but may not necessarily improve pitting resistance [2, 9 , 
10]. Furthermore, the growth kinetics for IGC may be different than for pitting.

Many questions regarding the nature of pitting and IGC in $\mathrm{Al}$ alloys are still unclear. Little is known about the transition between pitting and IGC and the factors responsible for this transition process. Another unresolved issue is how artificial aging affects the susceptibility of alloys to pitting and IGC. In this paper, the pitting and IGC behavior of AA2024 in different tempers was studied in $1 \mathrm{M} \mathrm{NaCl}$. The effect of nitrate and sulfate ions on the localized corrosion behavior was also studied. The purpose of this work was to identify the electrochemical factors that govern the susceptibility to IGC and control the transition from pits to IGC, and determine how artificial aging, solution environment, and anodic potential affect IGC initiation and growth from a micro structural point of view.

\section{Experimental}

Most specimens were prepared from commercial $1.9 \mathrm{~cm}$ thick AA2024-T3 plate stock. A few samples were taken from commercial $0.2 \mathrm{~mm}$ thick AA2024-T3 sheet material. For the plate material, samples with three different orientations, i.e. longitudinal (L), long transverse (LT) and short transverse (ST) sections were prepared using a band saw or diamond saw. The T3+, T8, and $\mathrm{T} 8+$ tempers were produced by artificially aging AA2024-T3 slices, previously cut from the plate, at $190^{\circ} \mathrm{C}$ in an air furnace for $2.5 \mathrm{~h}, 12 \mathrm{~h}$, and $36 \mathrm{~h}$, followed by air cooling, respectively. Solution heat treated (SHT) AA2024 samples were also prepared from the as-received AA2024T3 plate and sheet materials. The solution heat treatment was conducted in an air furnace at $492^{\circ} \mathrm{C}$ for $1 \mathrm{~h}$, followed by either water quenching or furnace cooling. The effect of artificial aging on the mechanical properties was determined using microhardness measurements. All samples for electrochemical experiments were ground mechanically and polished through a series of silicon carbide ( $\mathrm{SiC}$ ) papers (up to 800 grit) in ethanol. No water was used during polishing in order to minimize corrosion. After polishing, the samples were degreased with ethanol before attachment to the bottom of an acrylic cell by pressing against a teflon knife-edge O-ring to expose an area of about $1 \mathrm{~cm}^{2}$ for the experiments. The solution for most experiments was $1 \mathrm{M} \mathrm{NaCl}$. For a few experiments, a certain amount of nitrate or sulfate was added.

Anodic potentiodynamic polarization experiments were performed in deaerated $1.0 \mathrm{M}$ $\mathrm{NaCl}$ to determine the breakdown potentials of various tempers (SHT, T3, T3+, T8 and T8+) of AA2024 as a function of sample orientation relative to the rolling direction. The solution was Ardeaerated for at least $24 \mathrm{~h}$ before the polarization experiment, and was continuously purged with Ar during the measurement. Each sample was exposed to the solution for $35 \mathrm{~min}$ prior to the start of the measurement, and then potentiodynamically polarized from $-30 \mathrm{mV}$ below the open circuit potential to a potential above the breakdown potentials at $0.1 \mathrm{mV} \mathrm{s}^{-1}$. No IR compensation or correction was made during polarization measurement. The breakdown potentials were taken as the points in the anodic polarization curve at which the current increased sharply. Cyclic polarization and potentiostatic polarization experiments were also performed to examine the type of localized corrosion and repassivation behavior of pitting and IGC in Ar-deaerated pure chloride and nitrate containing chloride solutions.

The microstructures of AA2024-T3 and T8 were characterized using optical metallography, scanning electron microscopy (Philips XL30 FEG-SEM) and transmission electron microscopy (Philips CM200 TEM). Samples with the three different orientations (ST, L, and LT) were polished to $1 \mu \mathrm{m}$ diamond paste, followed by etching in Keller's reagent for about 30 to $50 \mathrm{~s}$. Foils for transmission electron microscope (TEM) examination were prepared by 
electropolishing in a twin-jet electropolishing apparatus using a 30\% nitric acid in methanol at 30 to $-50{ }^{\circ} \mathrm{C}$.

\section{Results and discussion}

\subsection{Micro structure of AA2024}

Fig. 1 shows optical micrographs of microstructures in the AA2024 plate and sheet. All tempers (SHT, T3, T3+, T8 and T8+) of the AA2024 plate have a typical elongated pancakeshaped grain structure. Grains were elongated in both the longitudinal and long transverse directions. This directionality of elongated grain structure is particularly important in regard to localized corrosion growth kinetics, which are discussed in another paper [11]. The average grain dimensions for AA2024-T3 plate at the 1/4 T section were approximately $50 \mu \mathrm{m}$ in the short transverse (ST) direction, $2000 \mu \mathrm{m}$ in the longitudinal (L) direction, and $300 \mu \mathrm{m}$ in the long transverse (LT) direction. Grains were a little more elongated at the midsection of the plate. In contrast, the $0.2 \mathrm{~mm}$ thick AA2024-T3 sheet exhibited a completely recrystallized structure, as evidenced by an almost equiaxed grain structure along three alloy directions with an average grain size of 30-50 $\mu \mathrm{m}$ (Fig. 1(c)).

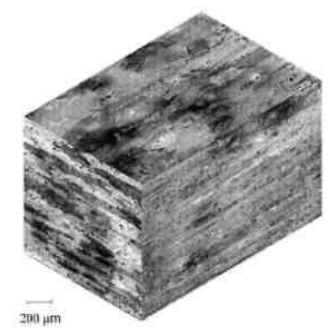

(a)AA2024-T3 plate
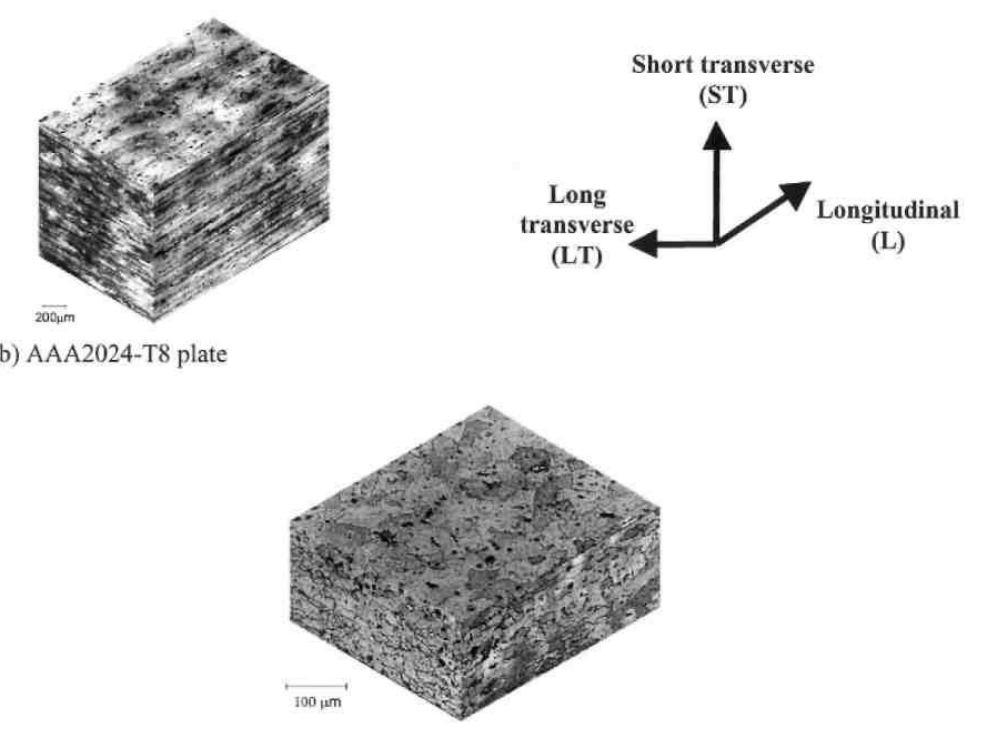

(c) AA2024-T3 sheet

Fig. 1. Microstructure of three orthogonal sections of (a) $1.9 \mathrm{~cm}$ thick AA2024-T3 plate, (b) AA2024-T8, (c) 0.2 
mm thick AA2024-T3 sheet.

In naturally aged AA2024-T3, it is believed that the matrix contains homogeneous coherent precipitates, denoted as GP zones, as well as fine hardening precipitates $\left(\mathrm{S}^{\prime} \mathrm{Al}_{2} \mathrm{CuMg}\right)$ [10,12]. Fig. 2 are typical TEM micrographs from the $1.9 \mathrm{~cm}$ thick plate showing the high density of plate shaped hardening precipitates $\left(\mathrm{S}^{\prime} \mathrm{Al}_{2} \mathrm{CuMg}\right)$ in AA2024-T3. In addition, scattered through the matrix are a lot of large and rod shaped particles containing $\mathrm{Al}, \mathrm{Mn}$, and $\mathrm{Cu}$ (possibly $\mathrm{Al}_{20} \mathrm{Mn}_{3} \mathrm{Cu}_{2}$ ). There was little evidence for the existence of precipitate-free zones (PFZ) along the grain boundaries in T3 temper although the formation of PFZ adjacent to the grain boundaries during quenching has been reported [10]. However, many rod shaped precipitate particles can be seen in GB regions, Fig. 2(b). They all had a similar shape, but were identified by $\mathrm{EDS}$ as having different compositions: very close to $\mathrm{Al}_{2} \mathrm{Cu}$ (very little $\mathrm{Mg}$ ), $\mathrm{Al}_{2} \mathrm{CuMg}$ or $\mathrm{Al}_{20} \mathrm{Mn}_{3} \mathrm{Cu}_{2}$ with no $\mathrm{Mg}$. Occasionally, Al-Cu-Mn-Fe particles were also found at the grain boundaries. It is believed that the rod shaped precipitate particles containing $\mathrm{Mn}$ and $\mathrm{Cu}$ form during solidification, not from aging, whereas others precipitate during natural aging [13]. The $\mathrm{Mn}$ and $\mathrm{Cu}$-rich particles are thought to pin grain boundaries, thus retarding recrystallization, and resulting in the retention of the elongated grain structure [13].

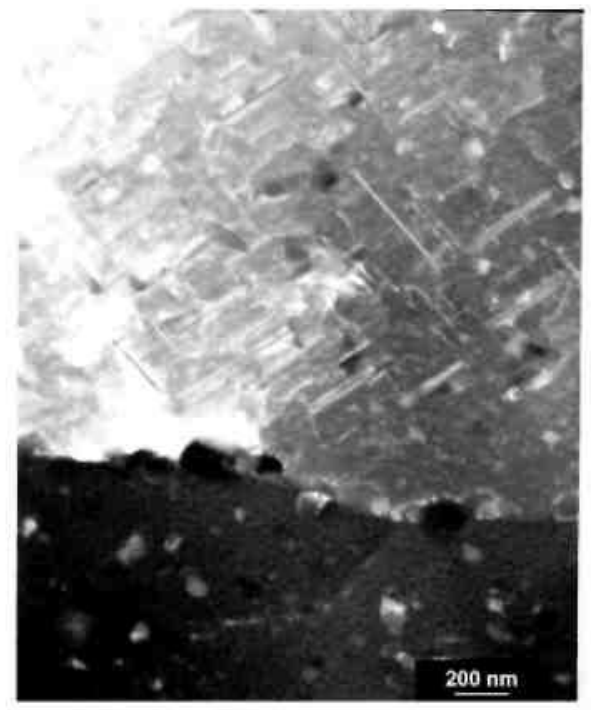

(a)

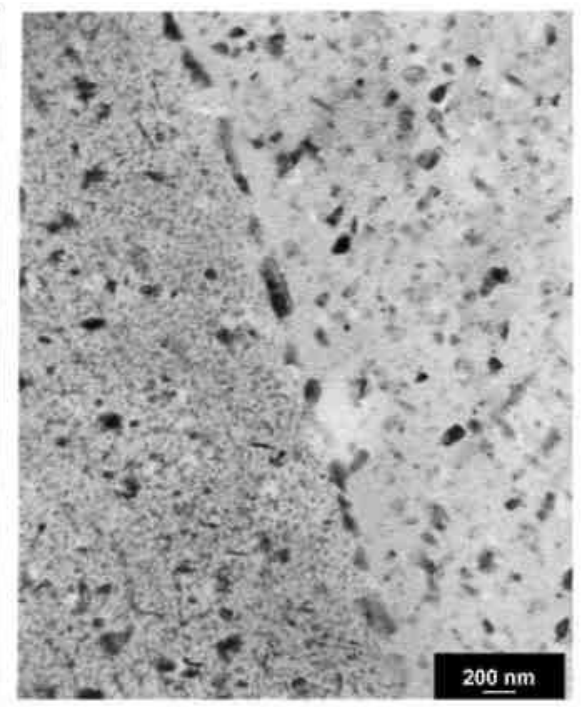

(b)

Fig. 2. Transmission electron micrographs of AA2024-T3 plate material showing (a) plate-like $\mathrm{S}^{\prime}\left(\mathrm{Al}_{2} \mathrm{CuMg}\right)$ precipitates, (b) rod-like precipitates in matrix and grain boundaries.

Microstructural changes that occur during solution heat treatment and artificial aging create corresponding changes in mechanical properties and corrosion behavior. The detailed microstructural changes can be quite complicated, including particle dissolution, particle coarsening, precipitation, changes in dislocation distribution and density, as well as changes of composition and structure in subgrain and grain boundaries. In general, artificial aging will not have much effect on the coarse constituent particles. The rod-like dispersoids, once formed, usually resist either dissolution or coarsening as well [13]. However, GP zones and the fine hardening precipitates $\left(\mathrm{S}^{\prime} \mathrm{Al}_{2} \mathrm{CuMg}\right)$ will change with aging. Solution heat treatment will dissolve these hardening precipitates. The blocky $\mathrm{Fe}, \mathrm{Mn}$-rich and coarse $\mathrm{Al}-\mathrm{Cu}-\mathrm{Mg}$ constituent particles are also not soluble at solution treatment temperature. It is generally believed that artificial aging 
at $190{ }^{\circ} \mathrm{C}$ allows more precipitation of $\mathrm{S}^{\prime}$ from GP zones in the matrix [13]. Fig. 3 shows such fine and numerous precipitate $\mathrm{S}^{\prime}$ platelets in AA2024-T8. The $\mathrm{S}^{\prime}$ precipitate platelets are still partially coherent with the matrix, and they can grow to more than $10 \mathrm{~nm}$ in thickness before transforming into incoherent $S$ phase particles $[14,15]$. No significant changes in matrix composition were revealed by EDS analysis as a result of artificial aging. Artificial aging will also cause preferential precipitation in the grain and subgrain boundaries, leading to the formation of PFZ around the grain boundaries. Fig. 3(b) is a TEM image illustrating such copper-depleted zones adjacent to the GB precipitates in AA2024-T8.

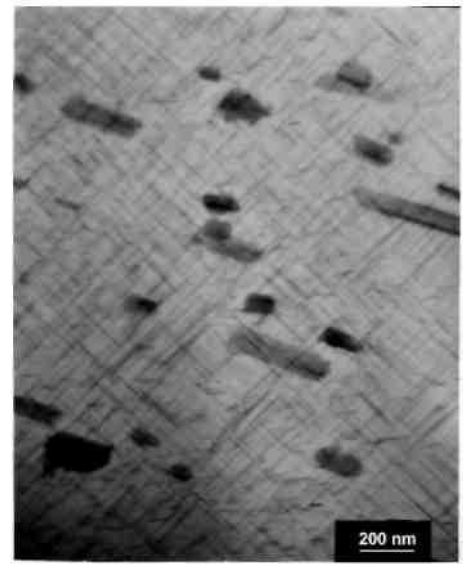

(a)

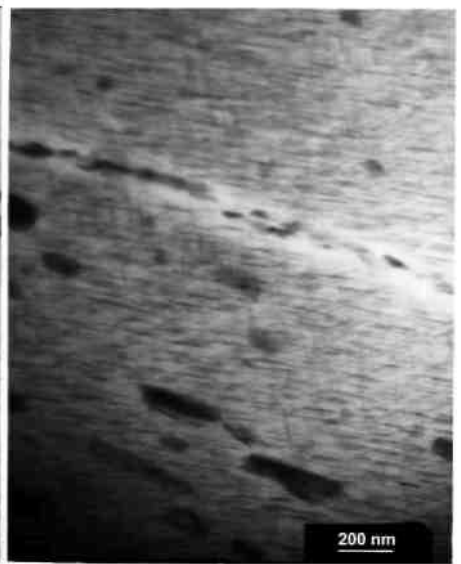

(b)

Fig. 3. Transmission electron micrographs of AA2024-T8 showing (a) plate-like $\mathrm{S}^{\prime}\left(\mathrm{Al}_{2} \mathrm{CuMg}\right)$ precipitates and rod shaped dispersoids in matrix, (b) PFZ around grain boundaries.

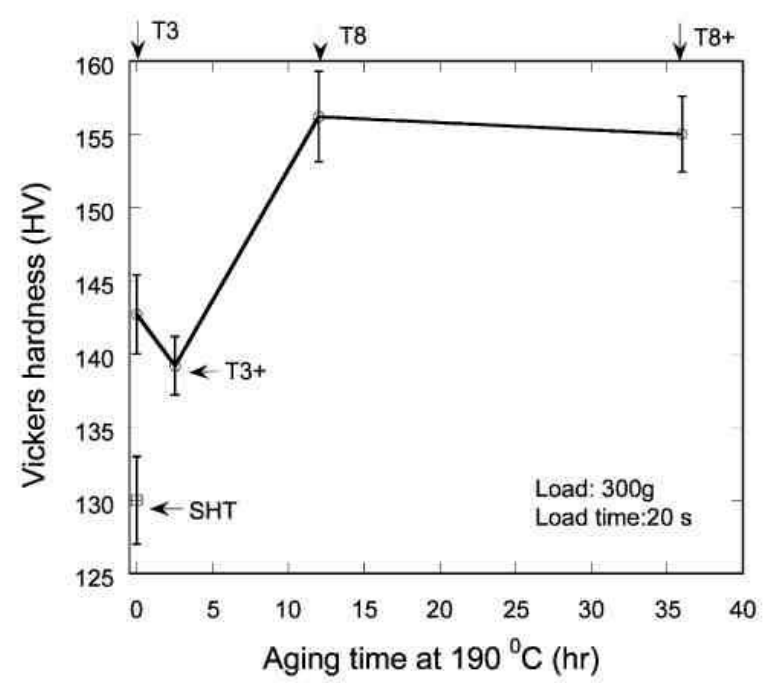

Fig. 4. Hardness-time curves for AA2024 aged at $190{ }^{\circ} \mathrm{C}$.

The effect of artificial aging on mechanical properties was evaluated using microhardness measurements. Fig. 4 shows the hardness changes for AA2024 aged for different times at $190^{\circ} \mathrm{C}$, which are in agreement with values reported in literature [10,12]. Hardness initially decreased during artificial aging due to partial reversion of the GP zones. After $12 \mathrm{~h}$ at $190^{\circ} \mathrm{C}$, a maximum 
in hardness was reached when the alloy contained a critical dispersion of GP zones and S' precipitates in the matrix. The over aged T8+ alloy showed a slight decrease in hardness because more incoherent $\mathrm{S}$ particles transformed from S' precipitates.

As mentioned above, the AA2024-T3 sheet had a recrystallized equiaxed grain structure and the plate had an elongated grain structure. Interestingly, fine sub-grain structure was also observed in the etched section of overaged AA2024-T8 plate, Fig. 5. Generally, a fine sub-grain structure is the result of a re-crystallization process (partially or fully) during alloy metallurgical and thermal processing [13]. However, recrystallization seems unlikely at the artificial aging temperature $\left(190^{\circ} \mathrm{C}\right)$. One alternative explanation is that artificial aging altered the subgrain boundary structure or composition so that they were revealed by chemical etching. The existence of PFZ adjacent to the grain boundaries as revealed by TEM observation on T8 temper also supports this view. From the above discussion, it is clear that artificial aging at $190^{\circ} \mathrm{C}$ changes the grain and GB composition, and microstructure of AA2024 alloys.

\subsection{Polarization curves}

Potentiodynamic polarization experiments were performed on ST, L, and LT samples in deaerated $1 \mathrm{M} \mathrm{NaCl}$ to test the influence of sample orientation. Fig. 6 shows that the current increases sharply above the first breakdown potential $E_{1}$ However, instead of increasing monotonically with increasing potential, the current reaches a maximum at a potential labeled $E_{\mathrm{c}}$ and then decreases by as much as a factor of 10 . Above a second breakdown potential, $E_{2}$, the current increases again. The two breakdown potentials are almost independent of the sample orientation and potential scan rate. The more active one, $E_{1}$, occurs at about -670 to $-700 \mathrm{mV}$ SCE, and the more noble one, $E_{2}$, occurs at about -590 to $-610 \mathrm{mV}$ SCE. $E_{\mathrm{c}}$ was in the range of 630 to $-650 \mathrm{mV}$ SCE. This current maximum is a reproducible feature of the potentiodynamic polarization curves for the three alloy directions of AA2024-T3.

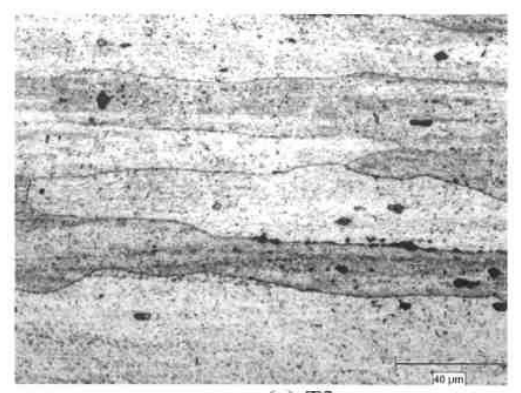

(a) $-\mathrm{T} 3$

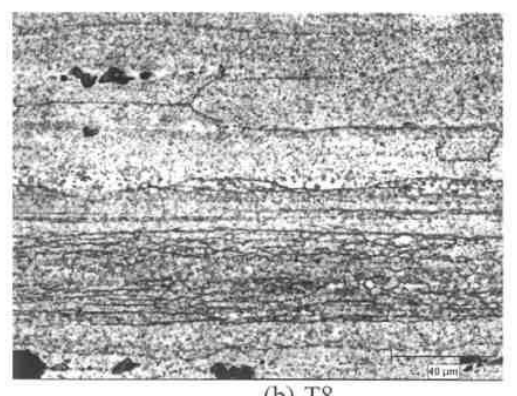

(b) - T8

Fig. 5. Optical micrographs of LT sections of (a) AA2024-T3 and (b) T8 showing pancake-shaped grain structure, 
and fine sub-grain structure in T8 temper alloy. 


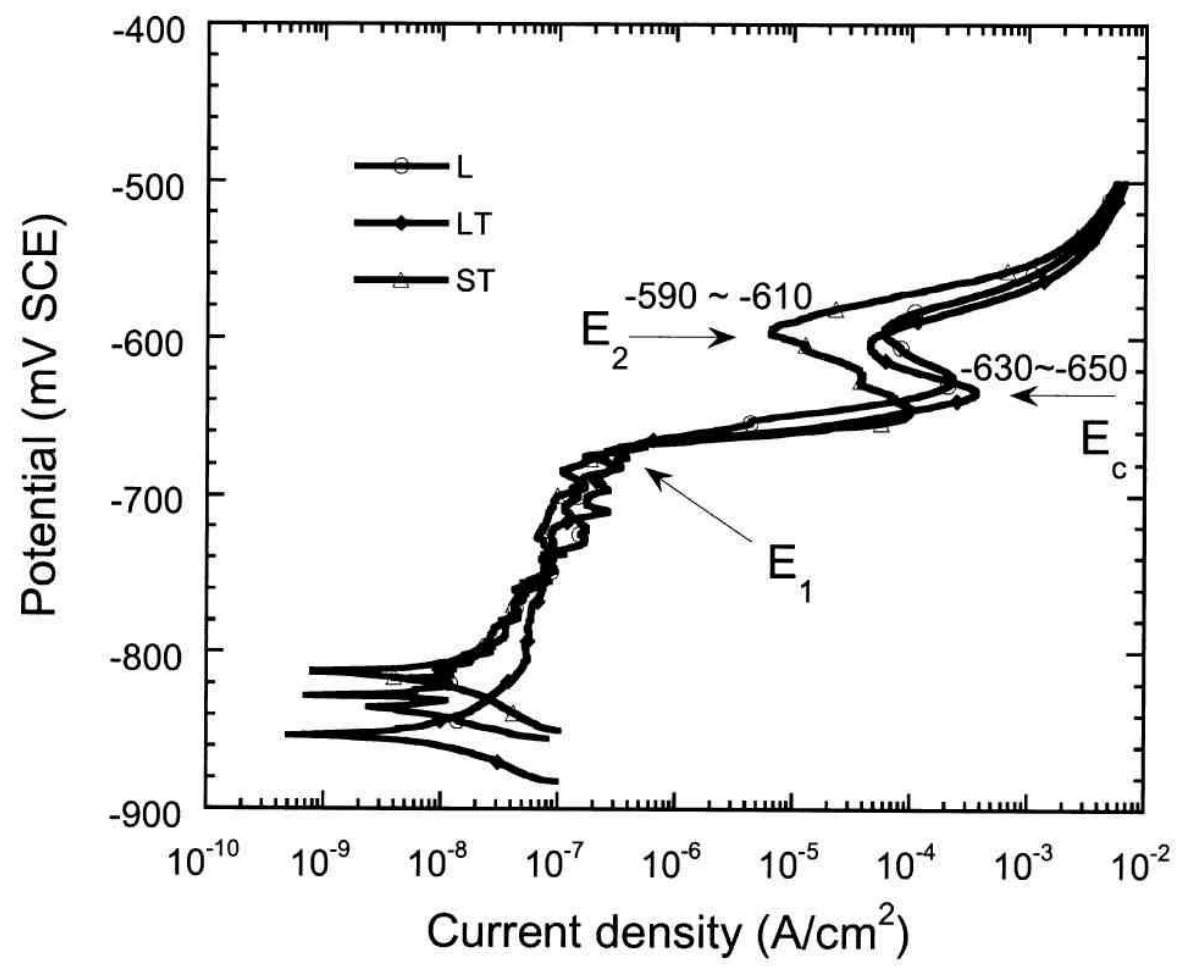

Fig. 6. Anodic polarization curves for AA2024-T3 in Ar-deaerated $1 \mathrm{M} \mathrm{NaCl}$ at a scan rate of $0.1 \mathrm{mV} \mathrm{s}^{-1}$.

Two breakdown potentials have been reported for aged Al-4\% $\mathrm{Cu}[1,8]$, AA7075-T6 [16,17], AA2017, AA2024 [6], and AA2024-T3 [18]. In aged Al-4\% Cu, Galvele and DeMicheli [1] found that first breakdown potential was associated with the dissolution of the Cu-depleted zone along the GB (i.e. IGC), and the noble one corresponded with pitting of the grain bodies. Sugimoto et al. [8] claimed the same mechanism for two breakdown potentials in aged $\mathrm{Al}-4 \% \mathrm{Cu}$ alloys. Maitra and English $[16,17]$ proposed a similar mechanism for two breakdown potentials observed for AA7075-T6 in deaerated 3.5\% NaCl solution. In addition, they found a much larger difference between these two breakdown potentials in a mixture of chloride, nitrate, and sulfate solutions as compared with that in pure chloride solutions. In Al-Cu-Mg alloys (AA2017 and AA2024) alloys, Urushino and Sugimoto [6] concluded that two breakdown potentials corresponded to pitting at the grain boundaries and the grain matrix, respectively. More recently, Guillaumin and Mankowski [18] proposed a slightly different view, arguing that the first breakdown potential of AA2024-T3 was related to the dissolution of coarse intermetallic $\mathrm{Al}_{2} \mathrm{CuMg}$ particles, while the second breakdown potential corresponded to the matrix breakdown potential. It will be shown below that our experimental results for AA2024-T3 are in agreement with the earlier study by Guillaumin and Mankowski [18] regarding the first breakdown potential, but suggest that the second breakdown potential results from initiation and growth of IGC. It should be pointed out that a two-breakdown potential polarization curve is a summation of current from two different localized dissolution processes. Even though we find that the second breakdown potential results primarily from IGC growth, IGC can initiate below the second breakdown potential. At lower potentials, the current associated with IGC is masked by the larger current associated with the transient $\mathrm{S}$ phase dissolution. So it should not be assumed that IGC is not possible below the second breakdown potential determined potentiodynamically. 


\subsection{Types of corrosion}

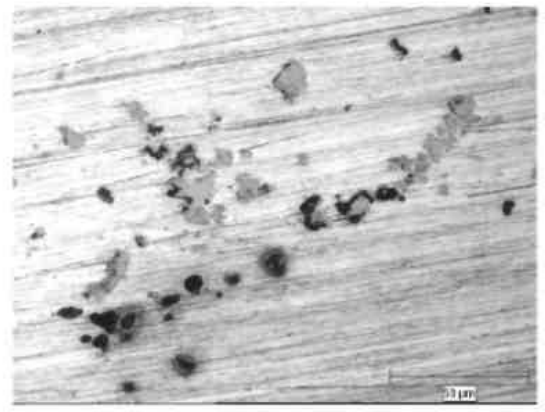

(a) $-690 \mathrm{mV}$ for $12 \mathrm{~h}$

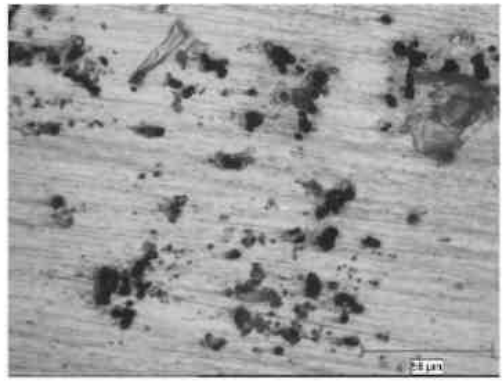

(c) $-660 \mathrm{mV}$ for $20 \mathrm{~h}$

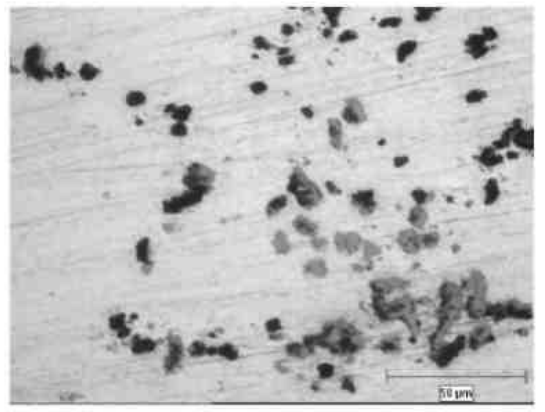

(b) $-670 \mathrm{mV}$ for $2 \mathrm{~h}$

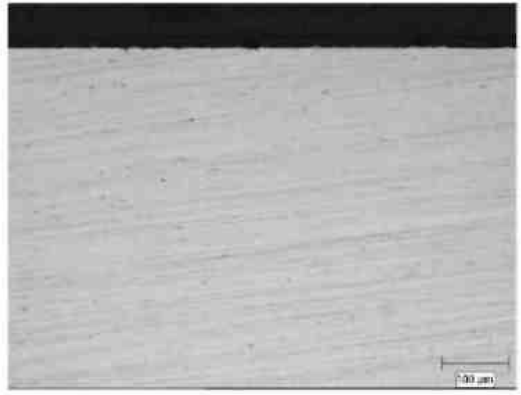

(d) Cross section, $-660 \mathrm{mV}$ for $20 \mathrm{~h}$

Fig. 7. Optical micrographs of the exposed surfaces of AA2024-T3 (ST) samples potentiostatically polarized, (a) at $690 \mathrm{mV} \mathrm{SCE}$ for $12 \mathrm{~h}$, (b) at $-670 \mathrm{mV} \mathrm{SCE}$ for $2 \mathrm{~h}$, (c) at $-660 \mathrm{mV} \mathrm{SCE}$ for $20 \mathrm{~h}$, and (d) cross section of the sample polarized at $-600 \mathrm{mV}$ SCE for $20 \mathrm{~h}$ in Ar-deaerated $1 \mathrm{M} \mathrm{NaCl}$ solutions.

Table 1

Summary of observations obtained from potentiostatic polarization and metallographic examination experiments

\begin{tabular}{|c|c|c|c|c|}
\hline Samples & $E$ (mV SCE) & Time (h) & Attack types & Notes \\
\hline AA2024-T3 ST & $\begin{array}{r}-690\left(\sim E_{1}\right) \\
-670\left(>E_{1}\right) \\
-660\left(>E_{1}\right) \\
-645\left(\sim E_{c}\right) \\
-645\left(\sim E_{c}\right) \\
-620\left(>E_{c}\right) \\
-590\left(>E_{2}\right) \\
-560\left(>E_{2}\right) \\
-560\left(>E_{2}\right) \\
+-660 \\
+-660\end{array}$ & $\begin{array}{r}12 \\
2 \\
20 \\
5 \\
20 \\
5 \\
5 \\
0 \\
12 \\
65\end{array}$ & $\begin{array}{l}\text { No IGC, only pits } \\
\text { No IGC, only pits } \\
\text { No IGC, only pits } \\
\text { No IGC, only pits } \\
\text { IGC + pits } \\
\text { IGC + pits } \\
\text { IGC + pits } \\
\text { IGC + pits } \\
\text { IGC + pits } \\
\text { + Large pits } \\
\text { + Large pits }\end{array}$ & $\begin{array}{l}\text { Breakdown } \\
\text { potentials: } \\
\text { (mV SCE) } \\
E_{1}=-690 \\
E_{2}=-610\end{array}$ \\
\hline AA2024-T8 ST & $\begin{array}{l}-740\left(\sim E_{p}\right) \\
-730\left(>E_{p}\right) \\
-700\left(>E_{p}\right) \\
-675\left(\gg E_{p}\right) \\
-660\left(\gg E_{p}\right)\end{array}$ & $\begin{array}{r}0 \\
2 \\
0 \\
2 \\
0 \\
12 \\
3 \\
0 \\
2\end{array}$ & $\begin{array}{l}\text { Scalloped attack } \\
\text { Selected granular attack } \\
\text { Scalloped attack } \\
\text { Selected granular attack } \\
\text { Scalloped attack } \\
\text { Selected granular attack } \\
\text { Selected granular attack } \\
\text { Scalloped attack } \\
\text { Selected grantlar attack }\end{array}$ & $E_{p}=-740$ \\
\hline
\end{tabular}


The presence of two breakdown potentials in the anodic polarization curves is an important feature of localized corrosion of AA2024-T3 in chloride solution. Generally speaking, a breakdown potential corresponds to the dissolution potential of a metallurgical phase [16]. So two breakdown potentials indicates that there are two phases in the AA2024-T3 microstructure, with different dissolution potentials, responsible for two different forms of localized corrosion. The reason for the current peak, i.e. the decrease in current with increasing potential above $E_{\mathrm{c}}$, must also be explained. In order to determine the causes responsible for each of the breakdown potentials in the polarization curves of AA2024-T3, potentiostatic polarization experiments were performed. Samples were first potentiodynamically polarized at $0.1 \mathrm{mV} \mathrm{s}^{-1}$ from open circuit potential to a final potential between the first breakdown potential $\left(E_{1}\right)$ and the second breakdown potential $\left(E_{2}\right)$, and then held at the final potential for certain times. The exposed surfaces of the samples were subsequently examined by optical microscopy and SEM to determine corrosion morphology. In addition, some samples were metallographically crosssectioned for further information. Table 1 summarizes the observations made from the potentiostatic experiments and metallography. No IGC was observed at the first breakdown potential for the T3 temper. Fig. 7 shows the exposed surfaces of the samples after polarization to $690 \mathrm{mV} \mathrm{SCE}$ (held for $12 \mathrm{~h}$ ), $670 \mathrm{mV} \mathrm{SCE}$ (held for $2 \mathrm{~h}$ ), and $-660 \mathrm{mV} \mathrm{SCE}$ (held for $20 \mathrm{~h}$ ), which are above $E_{1}$ but below $E_{\mathrm{c}}$, the potential associated with the current maximum. The initial attack was found to be associated with the intermetallic particles at the sample surface. Fig. 8 shows SEM images of a sample potentiodynamically polarized to $660 \mathrm{mV} \mathrm{SCE}$, and then held for $20 \mathrm{~h}$. EDS analysis indicated that attacked $\mathrm{Al}-\mathrm{Cu}-\mathrm{Mg}$ particles (particles marked A-C in Fig. 8(a) and (b)) contained $\mathrm{Cl}$ and $\mathrm{O}$, but almost no $\mathrm{Mg}$. No IGC was found on either the exposed surface or cross section, but a large number of small pits was found on the exposed surface, Fig. 8(c). These pits were so shallow that it was hard to locate them in the cross section, Fig. 7(d). These results suggest that both matrix and GB regions remained unattacked around the first breakdown potential.

The corrosion morphology changed as the potential increased above the transition potential, Ec. IGC was still not observed after $5 \mathrm{~h}$ at $-645 \mathrm{mV} \mathrm{SCE}$ (which is about $E_{c}$ ), Fig. 9(a), but IGC did occur after $20 \mathrm{~h}$ at $-645 \mathrm{mV}$ SCE, Fig. 9(b), indicating that IGC can initiate below $E_{2}$ but an induction period for IGC formation may exist. After $5 \mathrm{~h}$ at $-590 \mathrm{mV} \mathrm{SCE}$, which is just above $E_{2}$, IG attack was observed on both the exposed surface and the cross section, Fig. 9(c). At potentials above the second breakdown potential, $E_{2}$, much less time was needed for IGC to initiate and grow into the microstructure. Fig. 10 shows the exposed surface morphology of a sample that was potentiodynamically polarized to $-560 \mathrm{mV}$ and then removed from solution. This potential is well above the second breakdown potential, and IG attack appeared in addition to pits on the surface. These observations are evidence for assigning pitting corrosion to $E_{1}$, and IGC to $E_{2}$.

The current density versus time curves obtained during the potentiostatic polarization experiments show different behavior for the T3 temper samples held at different potentials. Figs. 11 and 12 show the current density transients for the samples held at $-690,-670,-660,-645$, and $590 \mathrm{mV}$ SCE. At the potentials below the second breakdown potential, the current density increased initially because of the onset of pitting, but then decreased almost one order of magnitude within minutes. The final current density depended on the applied potential. For long exposure, such as $20 \mathrm{~h}$ at $-660 \mathrm{mV}$ SCE, the final current density was still on the order of several $\mu \mathrm{A} \mathrm{cm}{ }^{-2}$, a little higher than the passive current density. Recall that Fig. 7 showed the presence of numerous small pits after $20 \mathrm{~h}$ at $-660 \mathrm{mV} \mathrm{SCE}$. This suggests that there exits a kind of 
pitting, probably due to intermetallic particles such as $\left(\mathrm{Al}_{2} \mathrm{CuMg}\right)$ or surface defects, which initiates quickly but grows very slowly in the potential range from $E_{1}$ to $E_{\mathrm{c}}$. It is possible that the pits are simply dissolved out $\mathrm{S}$ phase particles that do not lead to stable pit growth. This behavior is a kind of metastable pit growth. At $-590 \mathrm{mV} \mathrm{SCE}$, which is just above $E_{2}$, however, the current density showed totally different behavior. There was no initial peak in current density. Instead, the current density increased slowly with time until a very high value was reached.

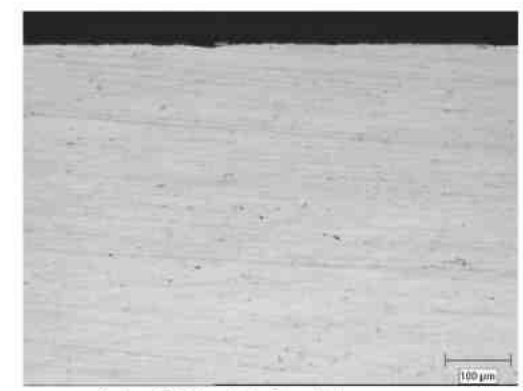

(a) $-645 \mathrm{mV}$ for $5 \mathrm{~h}$

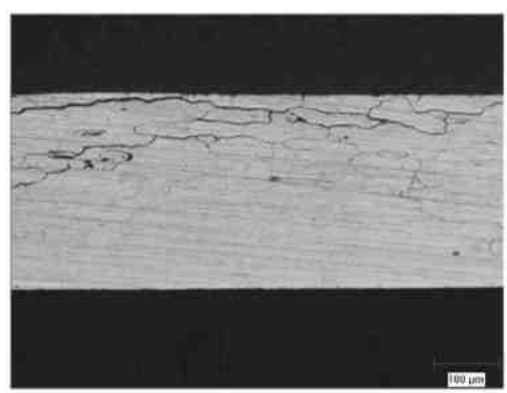

(c) $-590 \mathrm{mV}$ for $5 \mathrm{~h}$

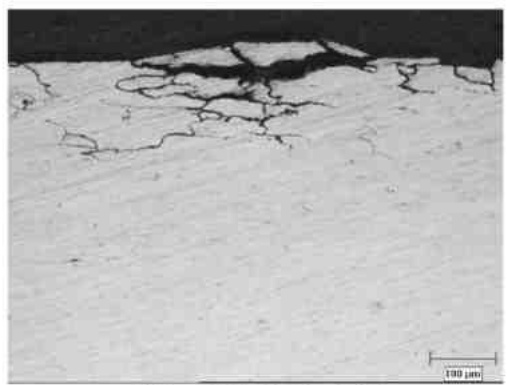

(b) $-645 \mathrm{mV}$ for $20 \mathrm{~h}$

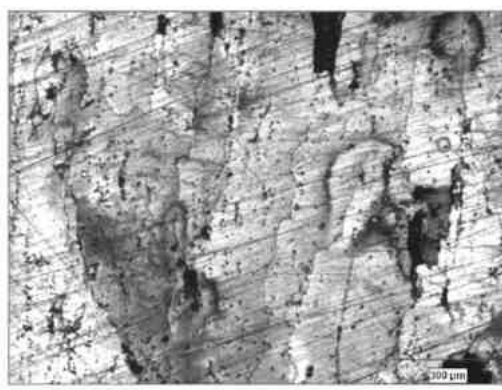

(d) exposed surface, $-590 \mathrm{mV}$ for $5 \mathrm{~h}$

Fig. 9. Metallographic cross sections of AA2024-T3 (ST) potentiostatically polarized at (a) -645 mV SCE for $5 \mathrm{~h}$, (b) $-645 \mathrm{mV} \mathrm{SCE}$ for $20 \mathrm{~h}$, (c) $-590 \mathrm{mV} \mathrm{SCE}$ for $5 \mathrm{~h}$, (d) exposed surface of the sample polarized at $-590 \mathrm{mV} \mathrm{SCE}$ for $5 \mathrm{~h}$ in Ar-deaerated $1 \mathrm{M} \mathrm{NaCl}$ solutions.

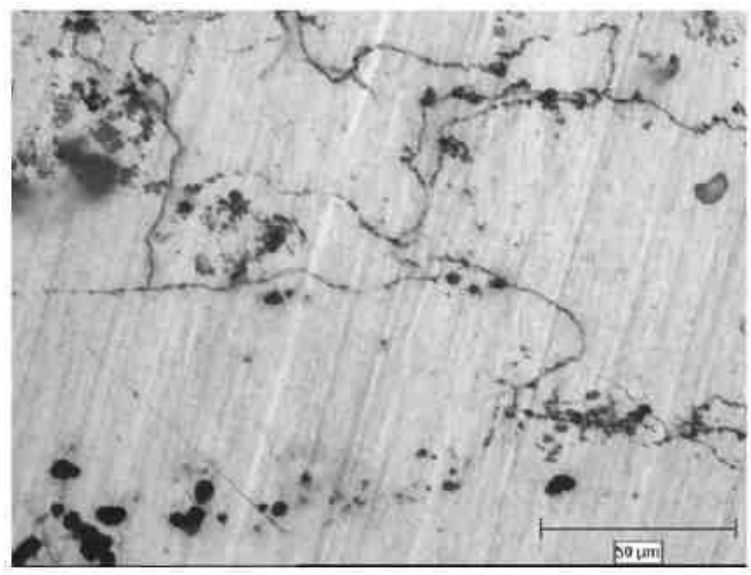

Fig. 10. Optical micrographs of the exposed surface of T3 (ST) sample potentiodynamically polarized to $-560 \mathrm{mV}$ $\mathrm{SCE}$ in Ar-deaerated $1 \mathrm{M} \mathrm{NaCl}$ solution. 


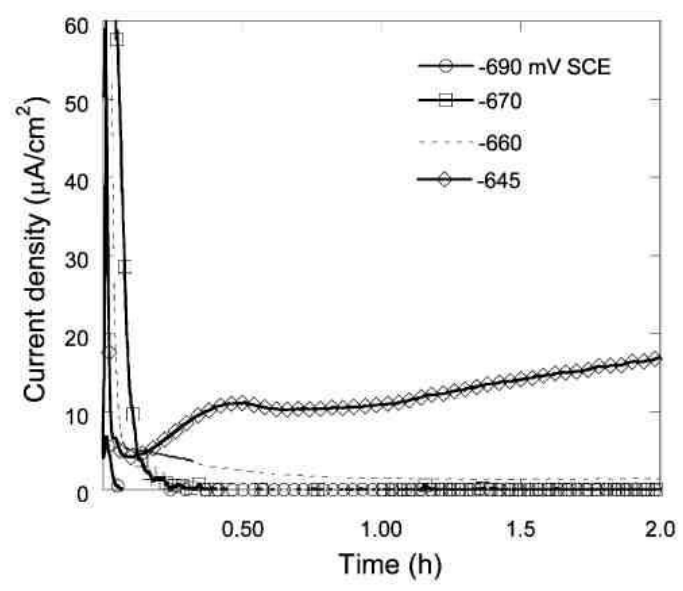

Fig. 11. Current density transients for AA2024-T3 (ST) samples held at potential range from -690 to -645 mV SCE, which is above the first breakdown and below the second breakdown potentials.

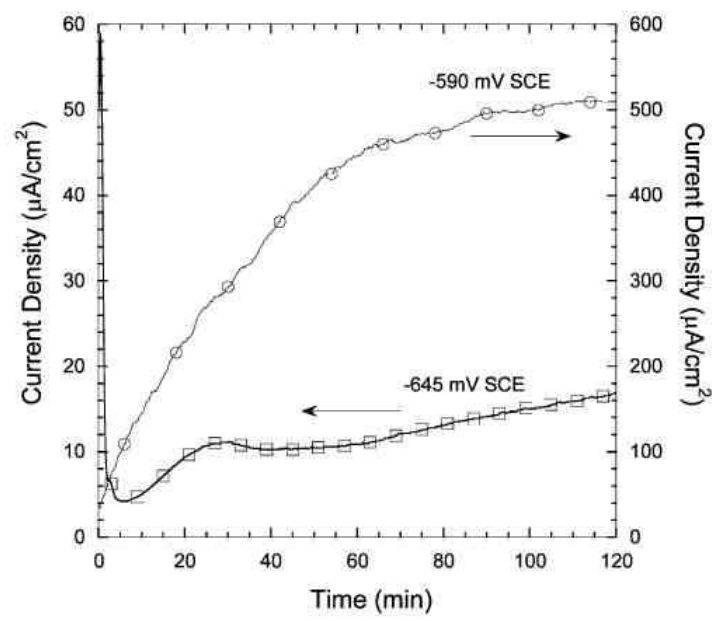

Fig. 12. Current density transients for AA2024-T3 (ST) samples held at -645 and $590 \mathrm{mV} \mathrm{SCE}$, respectively.

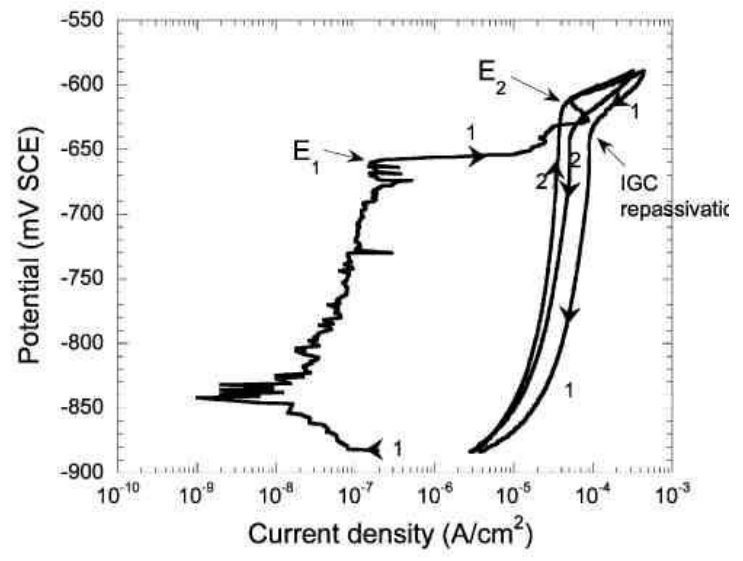

Fig. 13. Cyclic anodic polarization curves for the same AA2024-T3 (ST) sample in Ar-deaerated $1 \mathrm{M} \mathrm{NaCl}$ at a scan rate of $0.1 \mathrm{mV} \mathrm{s}^{-1}$. The sample was cyclically polarized twice from $50 \mathrm{mV}$ below OCP to $-590 \mathrm{mV}$ SCE. 
The behavior of the current density with time under potentiostatic polarization was consistent with the observation of a current maximum in the potentiodynamic polarization curves. Pits formed at the first breakdown potential, not IGC as reported in the literature $[1,16]$. These pits might be metastable, in that they form from the transient dissolution of $\mathrm{S}$ phase particles and then stop growing, or they might continue to grow very slowly. Like pitting, IGC has an incubation stage during its initiation. At the second breakdown potential, $E_{2}$, IGC initiated and grew very rapidly. Corrosion morphology that can be termed pitting is also evident at the higher potentials, suggesting that the metastable dissolution of $S$ phase particles can lead to stable pits if the potential is further increased.

Fig. 13 shows cyclic anodic polarization curves obtained on the same AA2024-T3 sample. The sample was first scanned from $50 \mathrm{mV}$ below the OCP to $-590 \mathrm{mV}$ SCE, back to the starting potential, and then scanned again through the same potential cycle. The first breakdown potential was not observed in the second scan; the single breakdown potential in the second scan is close to $E_{2}$ from the first scan. Clear determination of the breakdown potential in the second scan is complicated by the fact that the background current was higher. This higher current might result from an increase in the passive current density associated with a local increase in $\mathrm{pH}$, or it might be associated with a low level of continued localized attack as described as below. Regardless, the absence of the first breakdown potential during the rescan is further evidence that $E_{1}$ is associated with a transient process such as $\mathrm{S}$ phase dissolution, and not from a process that should be repeatable, such as IGC or matrix pitting.

Cyclic polarization experiments, followed by potentiostatic polarization, were used to examine the repassivation of localized corrosion during the reverse scan. Samples were first potentiodynamically polarized from the open circuit potential to $-520 \mathrm{mV} \mathrm{SCE}$, which is well above $E_{2}$, and then scanned in the reverse direction to $-620,-660$, or $-800 \mathrm{mV}$. The samples were either removed or held at the final potentials for $20 \mathrm{~h}$, and then metallographically cross sectioned to determine corrosion morphology. Fig. 14 shows some typical metallographic cross sections of those samples. It is clear that IG attack depth decreased with decreasing potential on the reverse scan, which suggests that IGC growth was not sustained when the potential was decreased to a certain value (repassivation potential for IGC). The attack morphology is more like pitting at -660 and $800 \mathrm{mV} \mathrm{SCE}$, which is consistent with measured lower net anodic current densities during the potentiostatic experiments, Fig. 15. Comparison of samples held at $660 \mathrm{mV}$ SCE for 0 and $20 \mathrm{~h}$ indicates that a low level of pitting corrosion may have continued. This suggests that pitting repassivates at a lower potential than IGC, but an explanation for this behavior is not clear.

It is generally accepted that IGC in high strength $\mathrm{Al}-\mathrm{Cu}$ and $\mathrm{Al}-\mathrm{Cu}-\mathrm{Mg}$ alloys is associated with precipitates in grain boundaries [1, 19]. Recent work by Ramgopal et al. [20] provides an explanation for the sharp IG attack. The solute depleted zones (SDZ) near the GB are considered to be the site for local attack, but $\mathrm{Cu}$-rich $\mathrm{S}$ phase particles at the $\mathrm{GB}$ are also attacked. These particles have been shown to release $\mathrm{Cu}$ [21]. Deposition of $\mathrm{Cu}$ on the grain faces lining the GB crevice would protect those faces from attack. Also, they provide a cathodic site that would consume current generated by IGC at the attack front. Since most of the current would not escape from the GB crevice, the dissolution rate of the front would not be strongly dependent on external applied potential. This also explains the independence of IGC growth kinetics on potential, which is discussed in another paper [11]. 


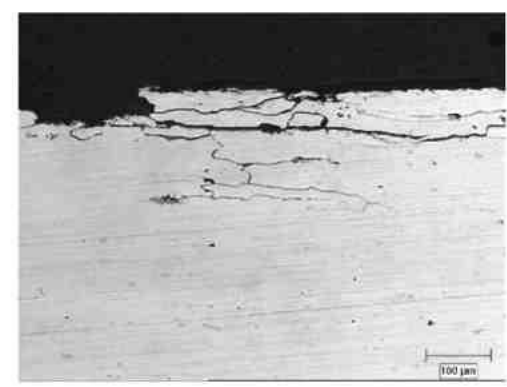

(a) $-620 \mathrm{mV}$ for $20 \mathrm{~h}$

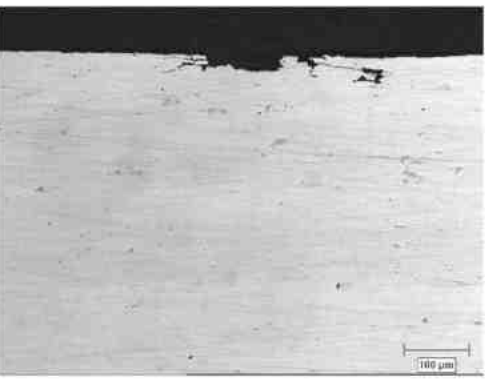

(c) $-800 \mathrm{mV}$ for $20 \mathrm{~h}$

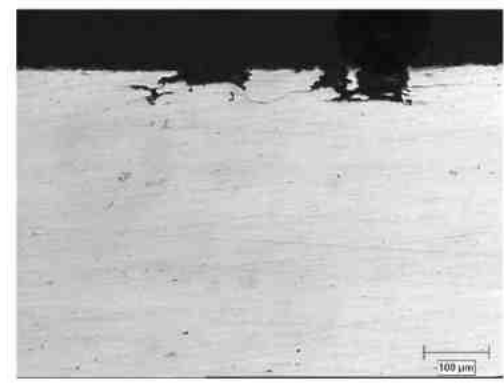

(b) $-660 \mathrm{mV}$ for $20 \mathrm{~h}$

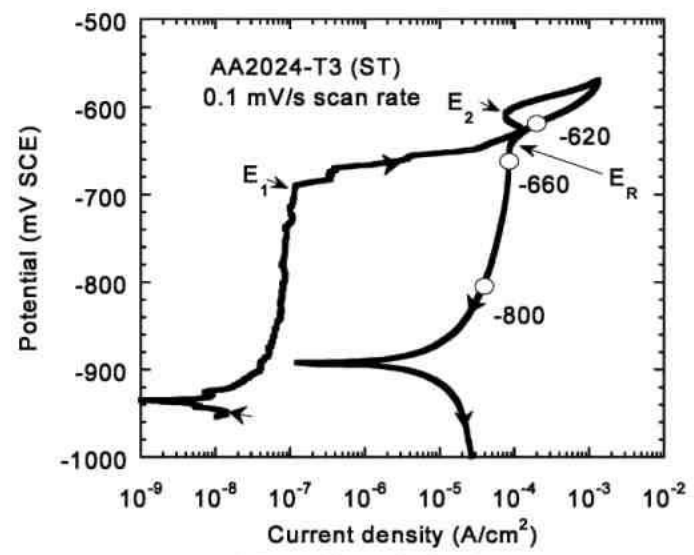

(d) cyclic polarization curve

Fig. 14. Metallographic cross sections of T3 samples potentiodynamically polarized to -620 on reverse scan and held the potential for $20 \mathrm{~h}$, (b) to -660 and held the potential for $20 \mathrm{~h}$, (c) to $-800 \mathrm{mV} \mathrm{SCE}$ and held the potential for $20 \mathrm{~h}$ in deaerated $1 \mathrm{M} \mathrm{NaCl}$, (d) cyclic polarization curve showing the potentials for the potentiostatic experiments.

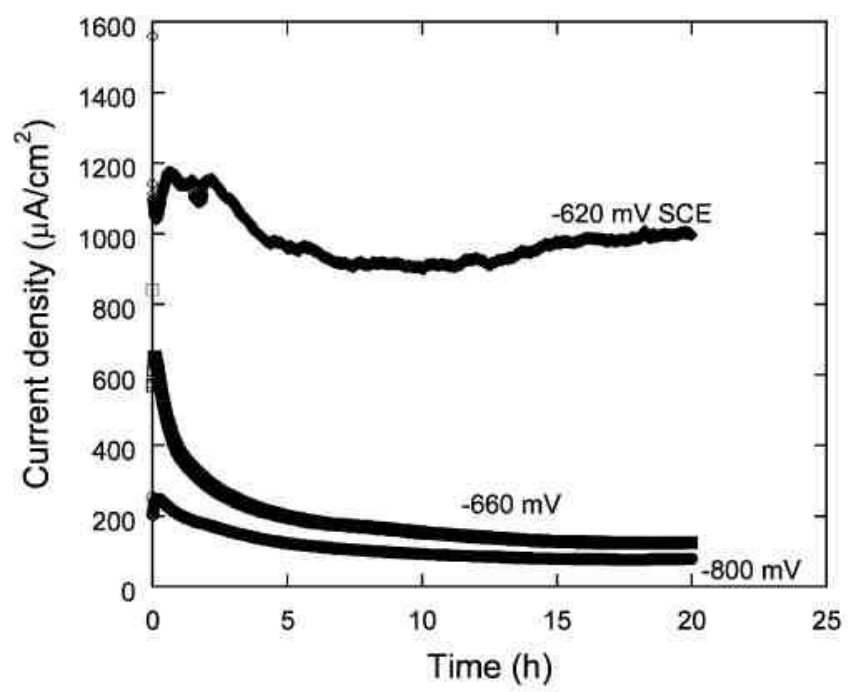

Fig. 15. The measured net current densities as a function of time for the potentiostatic experiment at -620 , -660 , and $-800 \mathrm{mV}$ SCE, respectively. 


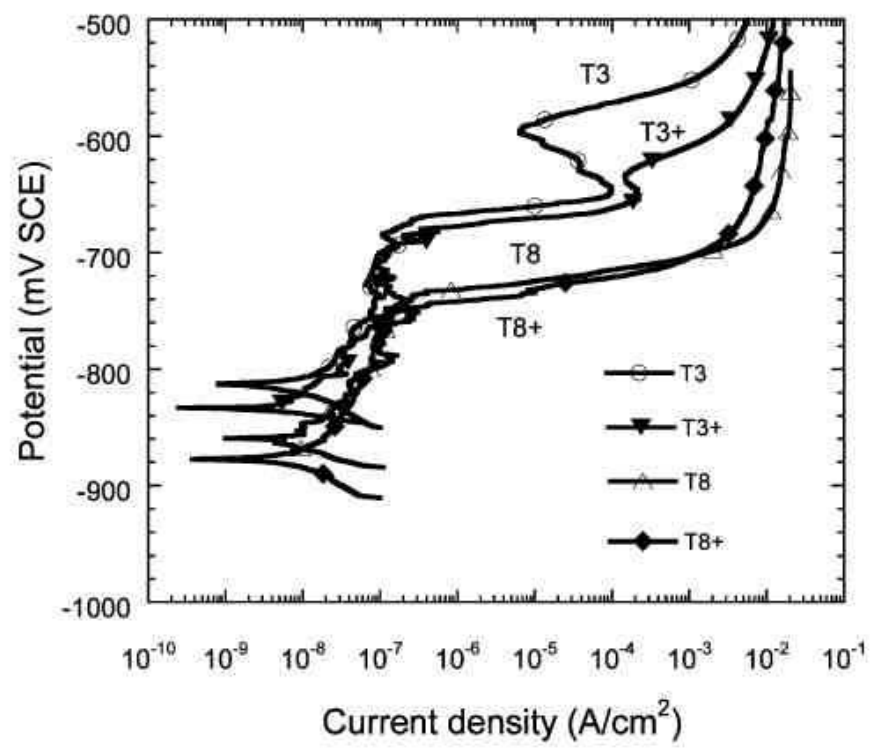

Fig. 16. Anodic polarization curves for various tempers of AA2024 (ST) in Ar-deaerated $1 \mathrm{M} \mathrm{NaCl}$ at a scan rate of $0.1 \mathrm{mV} \mathrm{s}^{-1}$.

\subsection{Effect of artificial aging}

The breakdown potentials were measured for aged AA2024 in three directions relative to the rolling direction after solution heat treatment and artificial aging. Fig. 16 shows some typical anodic polarization curves for various tempers of AA2024 (ST) samples obtained in $1 \mathrm{M} \mathrm{NaCl}$ at a scan rate of $0.1 \mathrm{mV} \mathrm{s}^{-1}$. The measured breakdown potentials are summarized in Tables 2 and 3. The reported values are the average of at least three separate experiments. As can seen from Fig. 16, artificially aging AA2024-T3 at $190{ }^{\circ} \mathrm{C}$ resulted in significant changes in the anodic polarization curves. The breakdown potentials decreased with increasing aging time. AA2024T3, T3+ and water-quenched SHT alloys exhibited two breakdown potentials, while only one breakdown potential was found for T8, T8+, and furnace-cooled AA2024-SHT alloys. Muller and Galvele [2] reported that aging $\mathrm{Al}-4 \% \mathrm{Cu}$ could produce a decrease of more than $100 \mathrm{mV}$ in the breakdown potential as a result of formation of $\mathrm{Al}_{2} \mathrm{Cu}$ intermetallic particles and depletion of copper from the matrix. In the case of AA2024, it is expected that aging allows more precipitation of fine intermetallic particles such as $\mathrm{S}$ phase from matrix, leaving a copperimpoverished matrix and forming copper-depleted zones along the subgrain and grain boundaries, both of which can decrease the breakdown potentials of the alloys. However, as described above, it is believed that $E_{1}$ and the corresponding current peak associated with $E_{\mathrm{c}}$ are a result of transient dissolution of large constituent $\mathrm{S}$ phase particles. This was proven for the T3 temper, and it is not expected that aging will affect the composition or behavior of these large constituent particles, or that fine newly precipitated $S$ phase particles have a lower breakdown potential. The metallographic evidence presented below indicates that copper depletion of the matrix with aging causes a reduction in the matrix breakdown leading to selected granular attack at low potentials for T8 and T8+ tempers. It is expected that transient dissolution of large constituent $S$ phase particles would still occur in the overaged tempers. However, the current associated with this behavior might be buried under the current associated with the selective matrix dissolution. 
Fig. 17 shows cross sections and the exposed surface for T8 ST orientated samples after potentiostatic polarization at $-740 \mathrm{mV}$ for $2 \mathrm{~h},-700 \mathrm{mV}$ for $12 \mathrm{~h}$ and $-675 \mathrm{mV}$ SCE for $3 \mathrm{~h}$, respectively. As seen from exposed surface SEM image, Fig. 17(a), the initial attack on the ST section is scalloped in appearance as a result of dissolution of select grains. The evidence for selective grain phase dissolution is much clearer from the cross sections, Fig. 17(b-d). The form of localized corrosion is neither $\mathrm{S}$ phase particle dissolution nor intergranular attack as the case of T3 temper. S phase particles did not dissolve at this potential as indicated by EDS analysis of $\mathrm{S}$ phase particle composition, Fig. 18(b). At $-660 \mathrm{mV}$ SCE, which is well above the T8 breakdown potential, the initial attack appears to be pit-like, Fig. 19(a), but after 2 h of exposure, severe dissolution of selected grains occurs as indicated from the exposed surface and the cross section, Fig. 19(b,c). There is a little inter-granular attack, but the intergranular attack does not propagate deeply into the microstructure. Further evidence for the selected granular attack can be seen in cross sections of L oriented T8 samples exposed at open circuit ( -740 mV SCE) for $15.9 \mathrm{~h}$ in oxygenated $1 \mathrm{M} \mathrm{NaCl}$ solution, Fig. 20(a). As-polished and etched cross sections show that the relatively wide and directional attack results from dissolution of individual elongated grains in the L orientation. The selected granular attack does not spread across the grain boundaries, but only propagates along the elongated grain direction, which is a totally different mechanism from that of T3, where attack initiated at grain boundaries and remained sharp at the grain boundaries. At a much higher potential such as $-580 \mathrm{mV} \mathrm{SCE}$, more grains were attacked, Fig. 20(b).

Table 2

Influence of orientation and potential scan-rate on breakdown potentials for AA2024-T3 and T8

\begin{tabular}{|c|c|c|c|c|c|c|c|}
\hline \multirow[t]{2}{*}{ Temper } & \multirow[t]{2}{*}{ Scan rate $\left(\mathrm{mV} \mathrm{s}^{-1}\right)$} & \multicolumn{3}{|c|}{$E_{1}(\mathrm{mV}$ SCE $)$} & \multicolumn{3}{|c|}{$E_{2}(\mathrm{~m} \vee \mathrm{SCE})$} \\
\hline & & ST & $\mathrm{L}$ & $\mathrm{LT}$ & ST & $\mathrm{L}$ & LT \\
\hline \multirow[t]{2}{*}{$T_{3}^{3}$} & 0.1 & $-691 \pm 17$ & $-687 \pm 11$ & $-691 \pm 16$ & $-610 \pm 15$ & $-605 \pm 10$ & $-610 \pm 7$ \\
\hline & 0.5 & $-695 \pm 14$ & $-680 \pm 18$ & $-690 \pm 19$ & $-604 \pm 8$ & $-602 \pm 5$ & $-604 \pm 6$ \\
\hline \multirow[t]{2}{*}{$\mathbf{T} 8$} & 0.1 & $\mathrm{~N} / \mathrm{A}$ & N/A & $\mathrm{N} / \mathrm{A}$ & $-739 \pm 6$ & $-737 \pm 4$ & $-740 \pm 9$ \\
\hline & 0.5 & $\mathrm{~N} / \mathrm{A}$ & N/A & $\mathrm{N} / \mathrm{A}$ & $-721 \pm 14$ & $-730 \pm 6$ & $-732 \pm 7$ \\
\hline
\end{tabular}

Table 3

Breakdown potentials for various tempered AA2024 (ST) alloys in Ar deaerated $1 \mathrm{M} \mathrm{NaCl}$ at scan rate $0.1 \mathrm{mV} \mathrm{s}^{-1}$

\begin{tabular}{llll}
\hline Temper & Heat treatment & $E_{1}$ (mV SCE) & $E_{2}(\mathrm{mV} \mathrm{SCE})$ \\
\hline$-\mathrm{T} 3$ & As-received & $-691 \pm 17$ & $-610 \pm 15$ \\
$-\mathbf{T} 3+$ & $2.5 \mathrm{~h}$ at $190^{\circ} \mathrm{C}$ & $-691 \pm 12$ & $-640 \pm 13$ \\
$-\mathbf{T} 8$ & $12 \mathrm{~h}$ at $190^{\circ} \mathrm{C}$ & $-739 \pm 6$ & \\
$-\mathbf{T} 8+$ & $36 \mathrm{~h}$ at $190^{\circ} \mathrm{C}$ & $-744 \pm 5$ & $-616 \pm 7$ \\
SHT & Solution heat treatment $1 \mathrm{~h}$ at $490^{\circ} \mathrm{C}$. water quench & $-708 \pm 13$ & $-728 \pm 5$ \\
SHT-F & Solution heat treatment $1 \mathrm{~h}$ at $490^{\circ} \mathrm{C}$. furnace cool & -728 & \\
\hline
\end{tabular}

If one value is given. only one breakdown was observed.

The selective grain attack seen on the T8 temper is consistent with the observation of decreased susceptibility to IGC with artificial aging [22]. The change in the form of attack can be explained by a decrease in $\mathrm{Cu}$ content of matrix phase with aging, which makes the grain more susceptible to breakdown than the GB or SDZ. However, it is interesting that the attack stays within single grains and does not spread to adjoining grains to become an isotropic hemispherical 
pit. It is possible that the less susceptible $\mathrm{GB}$ is protected by $\mathrm{Cu}$ deposition in the same fashion as was suggested above for the grain face during sharp IGC of T3 temper.

The two breakdown potentials appeared again after solution heat treatment and water quenching of the T8 temper, which further suggests the single breakdown potential that is found in the polarization curve for the T8 temper is not associated with dissolution of newly precipitated $\mathrm{S}$ phases, but from a process that is reversible by heat treatment such as matrix dissolution.

The current densities obtained during the potentiostatic experiments were very different for T8 samples than for T3 samples held around the first breakdown potential, Fig. 21. The current densities increased gradually with time, reaching high values that depended on the applied potential. This is similar to that found for $\mathrm{T} 3$ samples potentiostatically polarized around the second breakdown potential, Fig. 12. However, unlike T3 temper, no sharp IGC was observed in T8 samples polarized above the breakdown potential. The selected grain attack in the T8 temper suggests that artificial aging produces $\mathrm{Cu}$-depleted matrix and enhance the nobility of GB regions, reducing the IGC susceptibility in AA2024-T8.

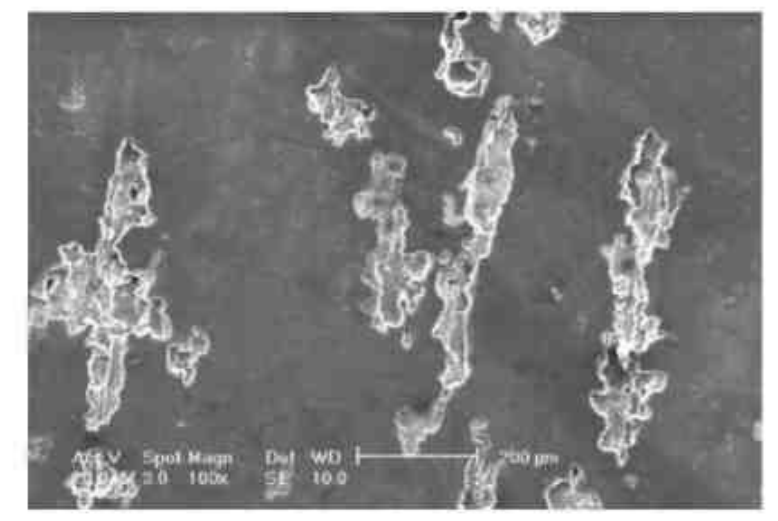

(a) SE image, $-740 \mathrm{mV}$ SCE for $2 \mathrm{~h}$.

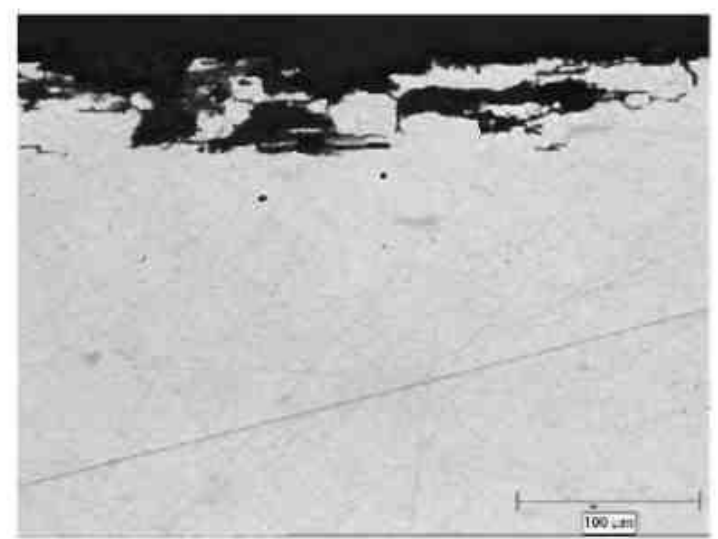

(c) Cross section, $-700 \mathrm{mV}$ SCE for $12 \mathrm{~h}$

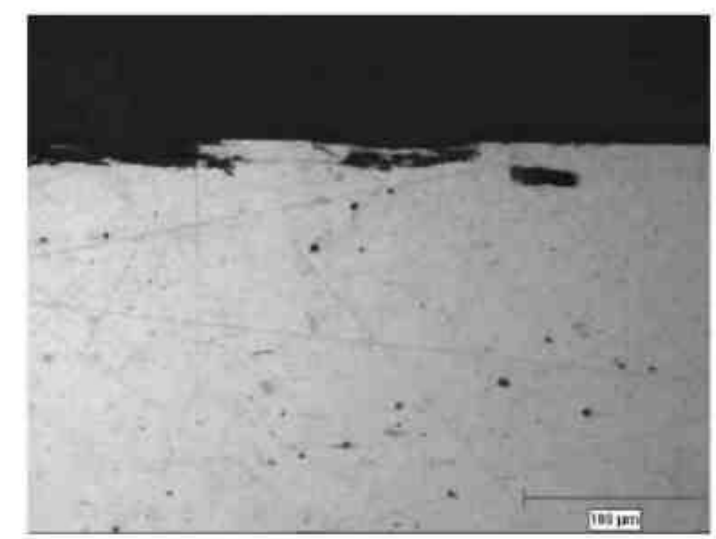

(b) Cross section, $-740 \mathrm{mV}$ SCE for $2 \mathrm{~h}$.

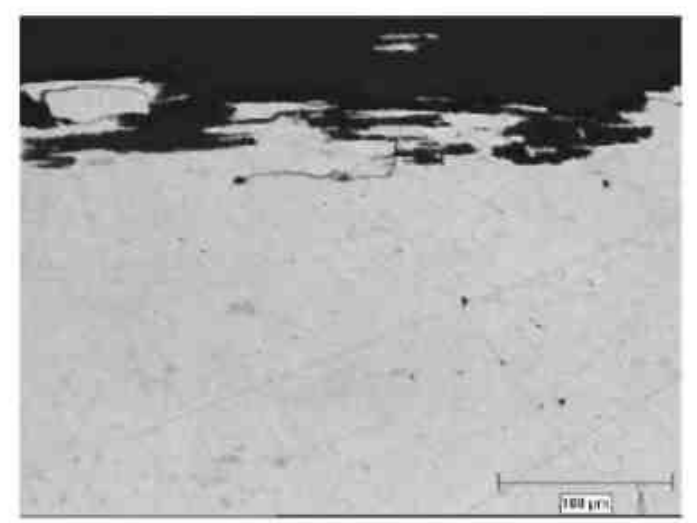

(d) Cross section, $-675 \mathrm{mV}$ SCE for $3 \mathrm{~h}$.

Fig. 17. (a) SEM image showing exposed surface and metallographic cross sections of ST orientated T8 samples potentiostatically polarized at, (b) $-740 \mathrm{mV} \mathrm{SCE}$ for $2 \mathrm{~h}$, (c) $-700 \mathrm{mV} \mathrm{SCE}$ for $12 \mathrm{~h}$, and (d) $-675 \mathrm{mV} \mathrm{SCE} \mathrm{for} 3 \mathrm{~h}$ in Ar-deaerated $1 \mathrm{M} \mathrm{NaCl}$ solutions. 


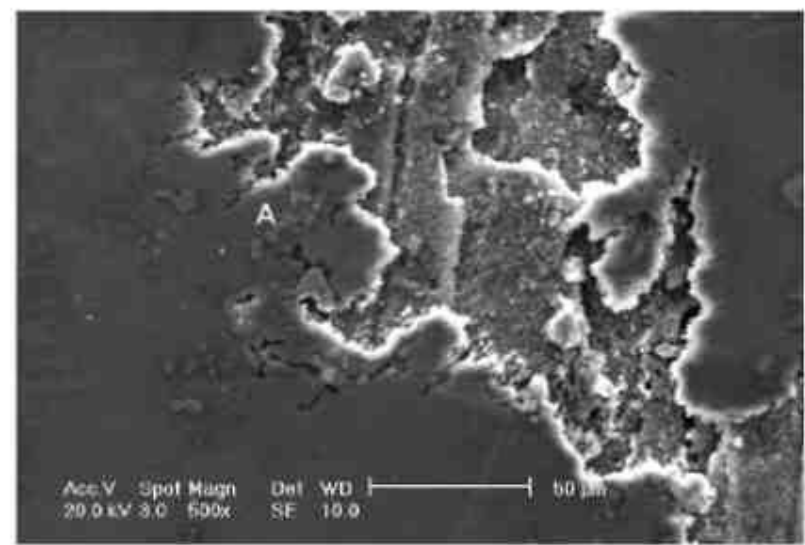

(a) SE image, $-740 \mathrm{mV}$ SCE for $2 \mathrm{~h}$.

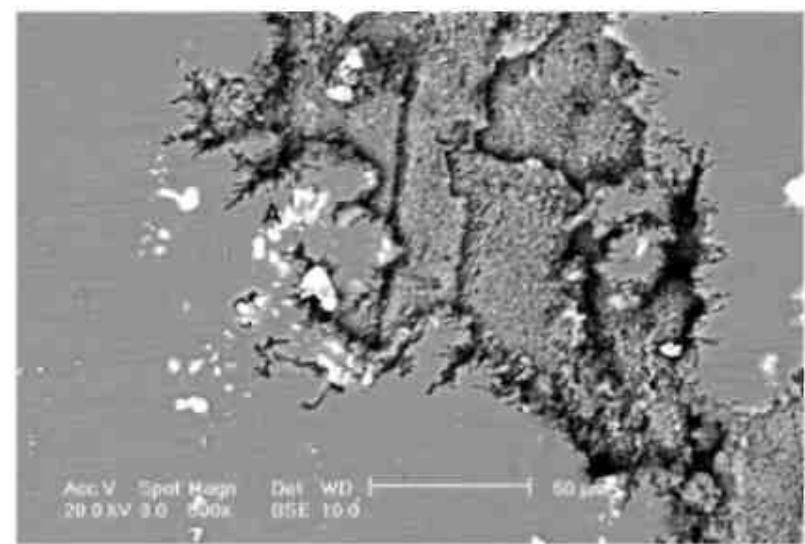

(b) BSE image, $-740 \mathrm{mV} \mathrm{SCE}$ for $2 \mathrm{~h}$.

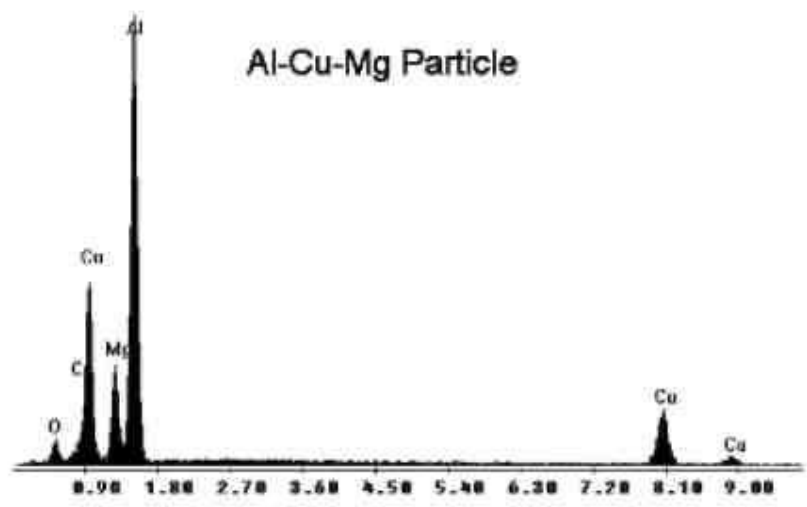

(c) EDS of unattacked S phase particle A

Fig. 18. SEM images (a), and (b) showing exposed surface of T8 sample potentiodynamically polarized to $-740 \mathrm{mV}$ SCE and followed by potentiostatic experiment at $-740 \mathrm{mV} \mathrm{SCE}$ for $2 \mathrm{~h}$, (c) EDS for undissolved Al-Cu-Mg particles.

As mentioned earlier, the AA2024-T3 alloy in sheet form had a different grain structure than the AA2024-T3 plate alloy. Artificial aging also resulted in the same effect on the polarization curves of the AA2024-T3 sheet material. 


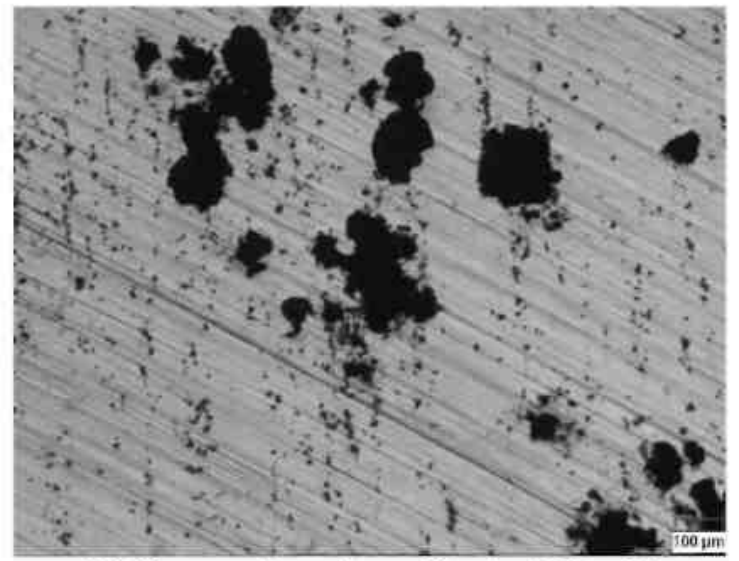

(a) Exposed surface, $0 \mathrm{~h}$ at $-660 \mathrm{mV}$

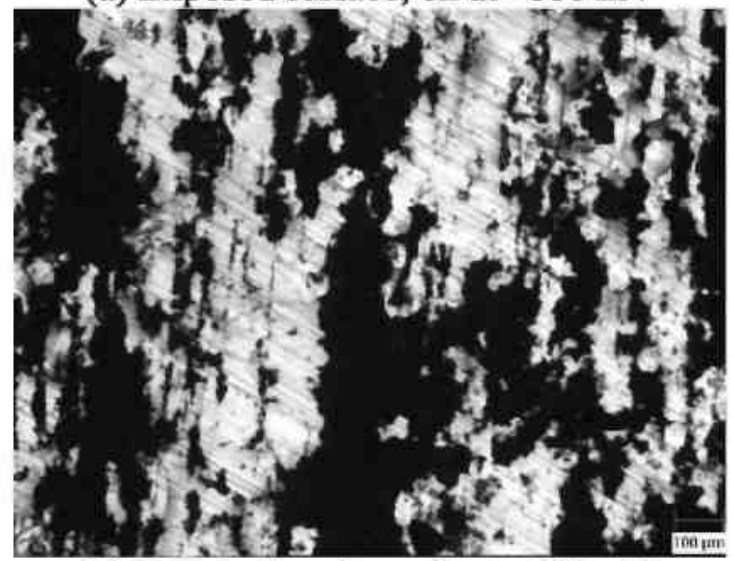

(b) Exposed surface, $2 \mathrm{~h}$ at $-660 \mathrm{mV}$

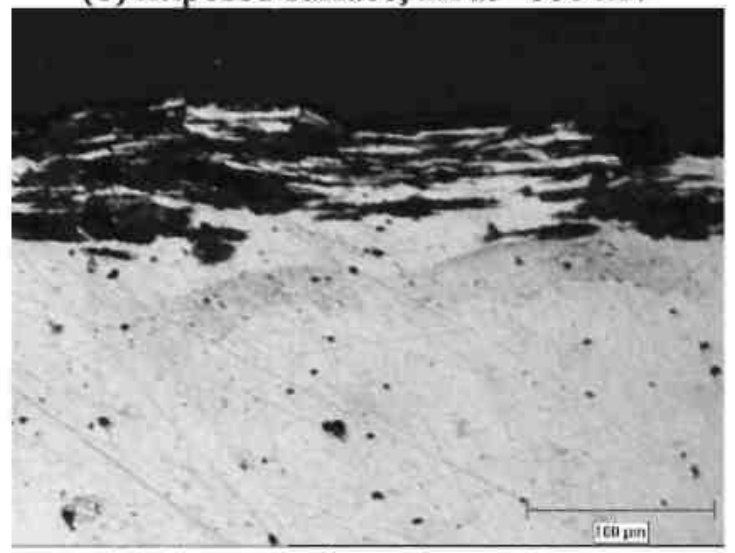

(c) Cross section, $2 \mathrm{~h}$ at $-660 \mathrm{mV}$

Fig. 19. Optical micrographs showing exposed surface of $\mathrm{T} 8$ sample, (a) potentiodynamically polarized to $-660 \mathrm{mV}$, (b) further held at -660 mV SCE for $2 \mathrm{~h}$, (c) cross section.

\subsection{Effect of nitrate and sulfate additions}

The effect of nitrate and sulfate addition on localized corrosion behavior was also studied since it was reported that, in addition to chloride ions, a relatively large amounts of nitrate and sulfate presented in real lap joints taken from airplanes [23]. It is generally accepted that nitrates 
can inhibit the pitting corrosion of $\mathrm{Al}$ and $\mathrm{Al}$ alloys in chloride solutions $[24,25]$. On the other hand, sulfate is reported to have little effect on pitting of Al alloys unless it is present at a very high concentration [24]. Fig. 22 compares cyclic polarization curves for AA2024-T3 ST samples in $1 \mathrm{M} \mathrm{NaCl}, 1 \mathrm{M} \mathrm{NaCl}+0.2 \mathrm{M} \mathrm{NaNO}_{3}$, and $1 \mathrm{M} \mathrm{NaCl}+0.5 \mathrm{M} \mathrm{Na}_{2} \mathrm{SO}_{4}$. The polarization curves for L and LT samples are similar to these of ST samples. It was found that both OCP and breakdown potential increased with increasing nitrate concentration. The nitrate addition also changed the polarization behavior of AA2024-T3 on the reverse scan, which suggests that the nitrate may affect the repassivation behavior of localized corrosion. In contrast, the high concentration sulfate addition produced little difference in anodic polarization behavior except that only one breakdown potential was found. The polarization curve on the reverse scan appeared to be unchanged.

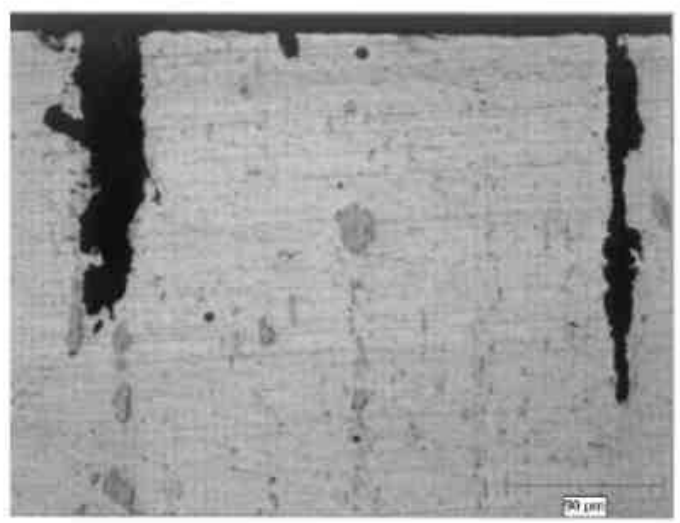

(as-polished)

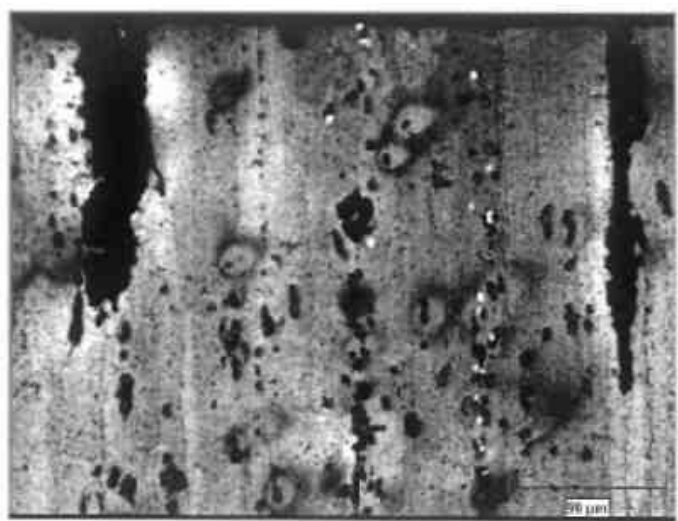

(etched)

(a) $-740 \mathrm{mV} \mathrm{SCE}$ (open circuit) for $15.9 \mathrm{~h}$

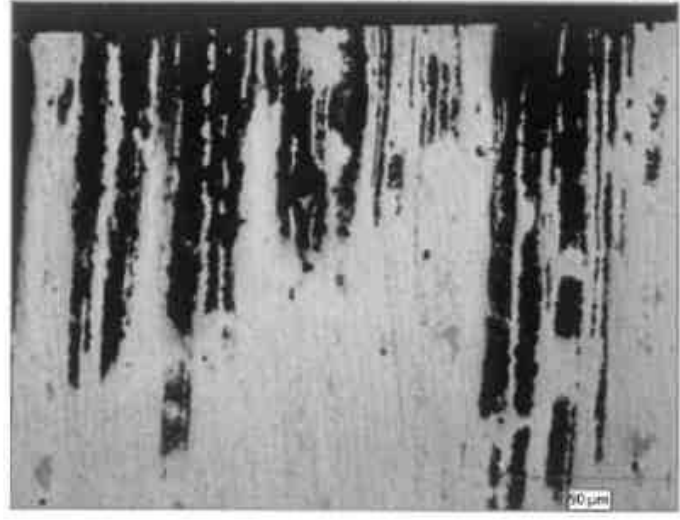

(as-polished)

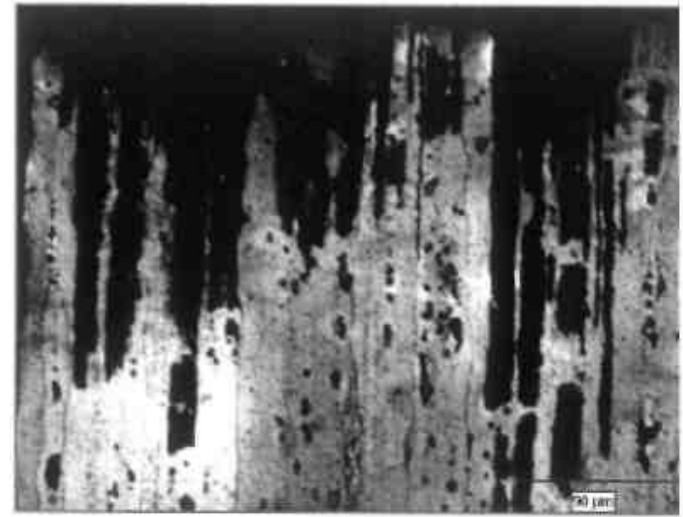

(etched)

(b) $-580 \mathrm{mV} \mathrm{SCE}$ for $5.5 \mathrm{~h}$

Fig. 20. Cross sections of L orientated T8 samples exposed at (a) open circuit ( -740 mV SCE for $15.9 \mathrm{~h}$, and (b) $580 \mathrm{mV} \mathrm{SCE}$ for $5.5 \mathrm{~h}$ in oxygenated $1 \mathrm{M} \mathrm{NaCl}$ solutions. 
Potentiostatic experiments were performed to further examine the type of corrosion on the reverse scan in nitrate containing chloride solutions. Again, samples were potentiodynamically polarized to a high value of $-400 \mathrm{mV} \mathrm{SCE}$, and then the scan was reversed. Fig. 23 shows that much deeper IGC attack was observed for the sample held at $-630 \mathrm{mV} \mathrm{SCE}$ for $20 \mathrm{~h}$ than for the samples given the same cyclic polarization treatment but without the subsequent potentiostatic polarization. This suggests that IGC can still grow at $-630 \mathrm{mV} \mathrm{SCE}$. There was not much difference in corrosion morphology between the samples held at -600 and $630 \mathrm{mV} \mathrm{SCE}$ for $20 \mathrm{~h}$ after the cyclic polarization. Both were primarily IGC and exfoliation with a similar depth into the microstructure. However, the measured net current densities exhibited totally different behavior, Fig. 24. The larger amount of anodic charge obtained at $-600 \mathrm{mV}$ SCE did not lead to deep and heavy IG attack, which suggests that the measured current density may not represent well the metal anodic dissolution kinetics under those conditions. It is possible that the local cathodic reaction greatly affects the net current measurement under potentiostatic conditions in nitrate containing chloride solutions.

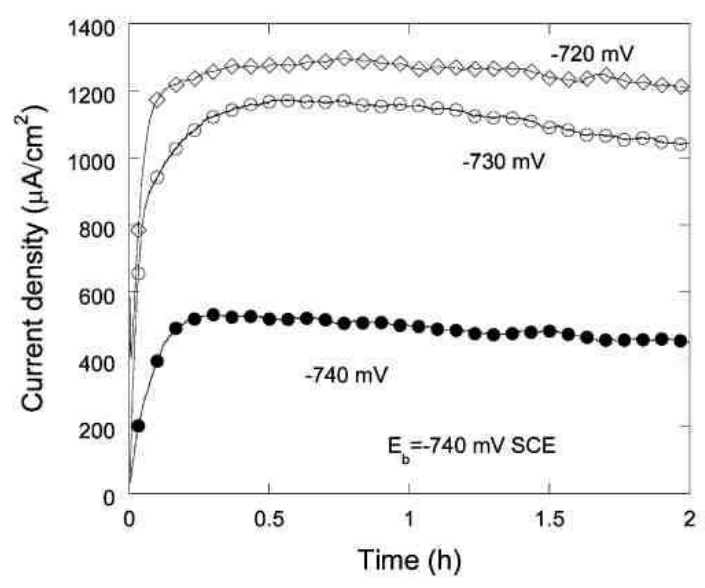

Fig. 21. Current density transients with time for AA2024-T8 at different potentials.

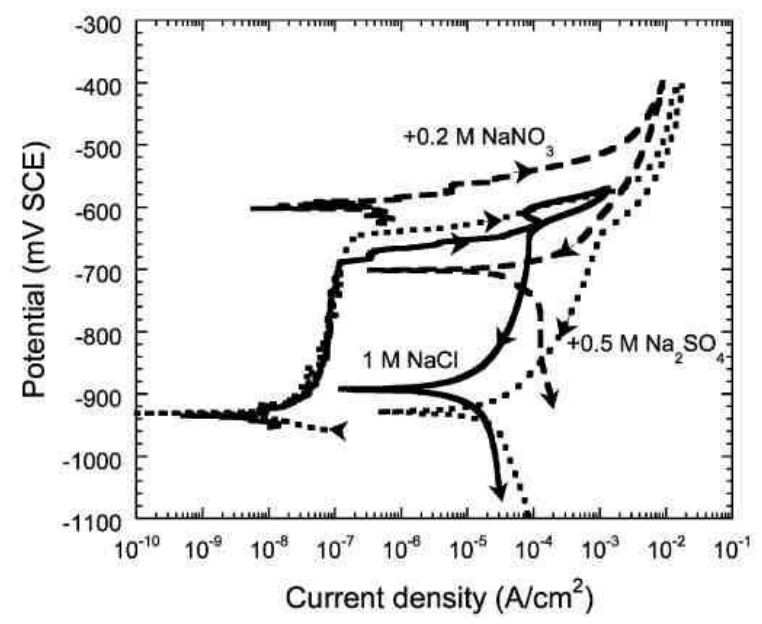

Fig. 22. Cyclic polarization curves for AA2024-T3 (ST) in deaerated $1.0 \mathrm{M} \mathrm{NaCl}, 1 \mathrm{M} \mathrm{NaCl}+0.2 \mathrm{M} \mathrm{NaNO}_{3}$, and 1 $\mathrm{M} \mathrm{NaCl}+0.5 \mathrm{M} \mathrm{Na}_{2} \mathrm{SO}_{4}$ solutions. 
The disappearance of the second breakdown potential in nitrate + chloride and sulfate + chloride solutions may be a result of an increase in the first breakdown potential, since two breakdown potentials were still visible in the chloride solution containing a small amount of nitrate and sulfate, Fig. 25. The addition of nitrate only affects $S$ phase particle dissolution process by increasing its dissolution potential, but has little effect on IGC growth kinetics as is discussed in another paper [11]. Potentiostatic polarization at $-580 \mathrm{mV}$ also results in IG attack as shown in Fig. 26. However, the density of IG attack on the cross section was obviously much lower as compared with heavy IG attack at $-580 \mathrm{mV}$ SCE in pure chloride solution. This suggests that initiation of IGC is more difficult in nitrate + chloride environment due to the increase in the breakdown potential. Unlike nitrate, addition of sulfate up to $0.5 \mathrm{M}$ appeared to have little effect on anodic polarization behavior of AA2024-T3. The effect of sulfate addition on IGC growth kinetics is discussed in another paper [11].

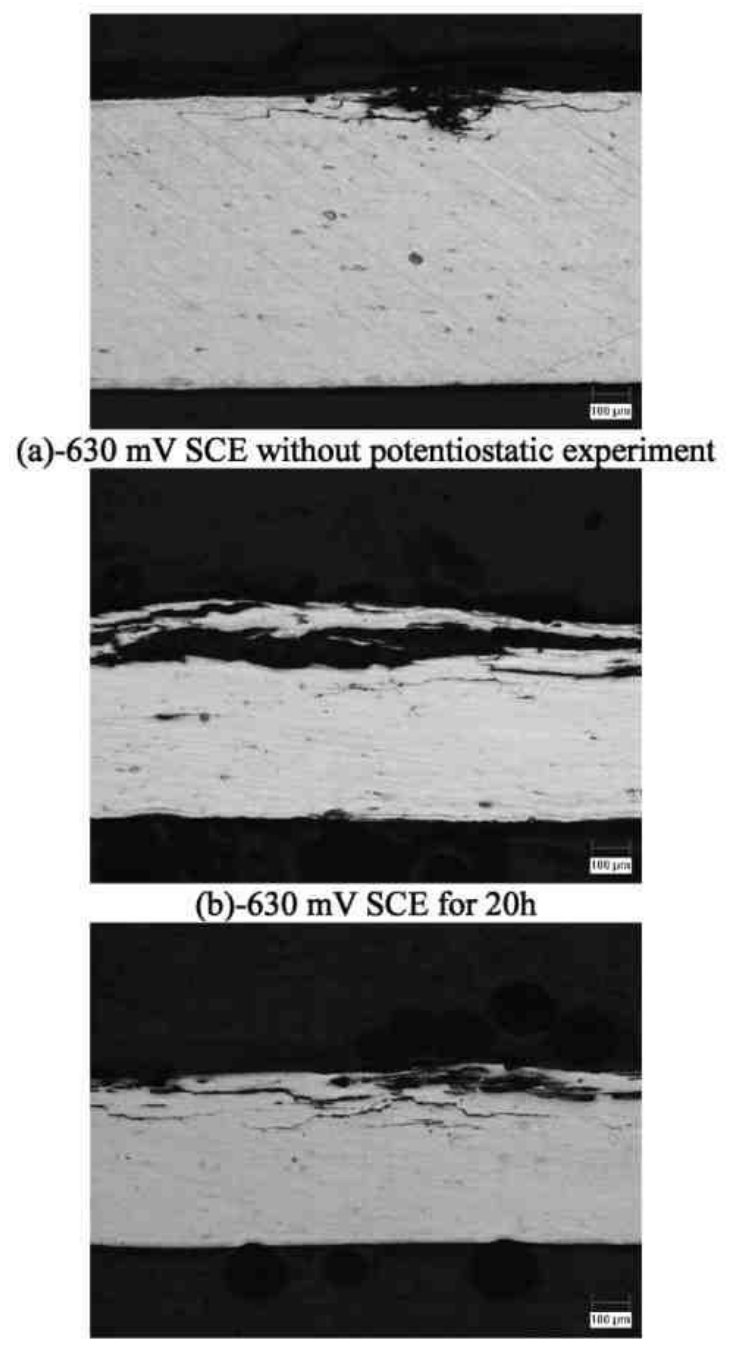

(c)-600 mV SCE for $20 \mathrm{~h}$

Fig. 23. Metallographic cross sections of T3 (a) cyclic potentiodynamically polarized to $-630 \mathrm{mV}$ SCE on reverse scan, (b) to $-630 \mathrm{mV} \mathrm{SCE}$ and held the potential for $20 \mathrm{~h}$,(c) to $-600 \mathrm{mV}$ and held the potential for $20 \mathrm{~h}$ in deaerated $1 \mathrm{M} \mathrm{NaCl}+0.2 \mathrm{M} \mathrm{NaNO}_{3}$. 


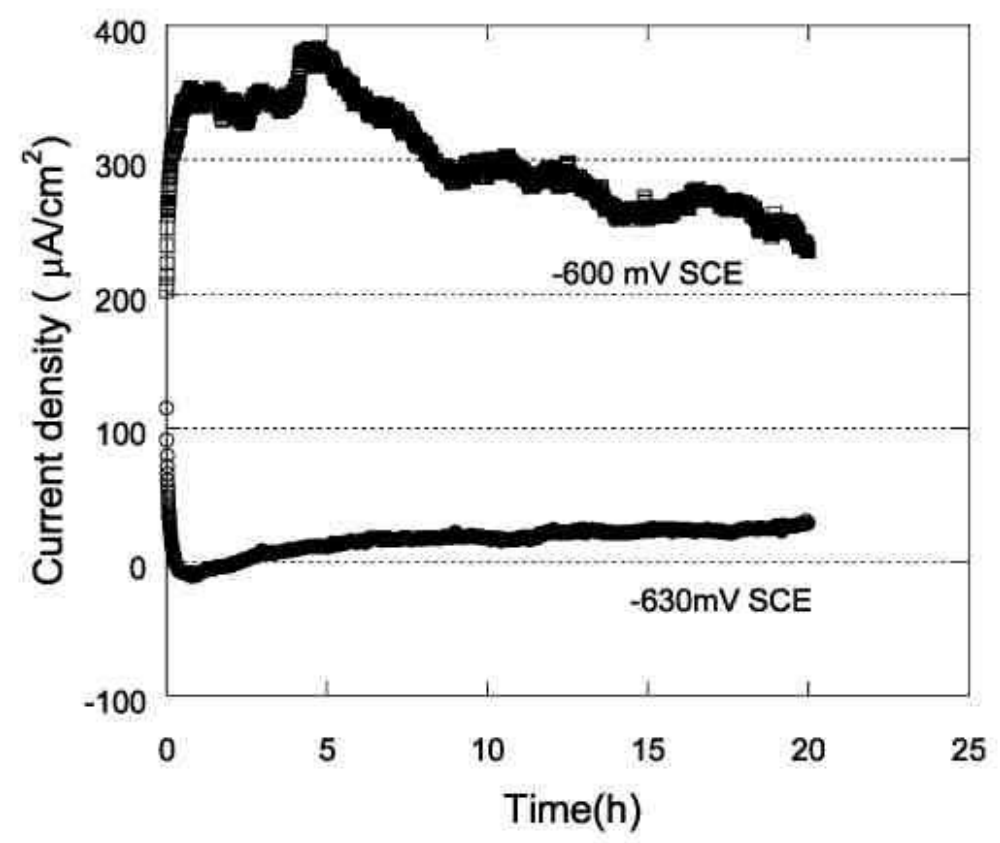

Fig. 24. Current density as a function of time for AA2024-T3 (ST) samples held at -600 and $-630 \mathrm{mV}$ SCE on reverse scan in deaerated $1 \mathrm{M} \mathrm{NaCl}+0.2 \mathrm{M} \mathrm{NaNO}_{3}$.

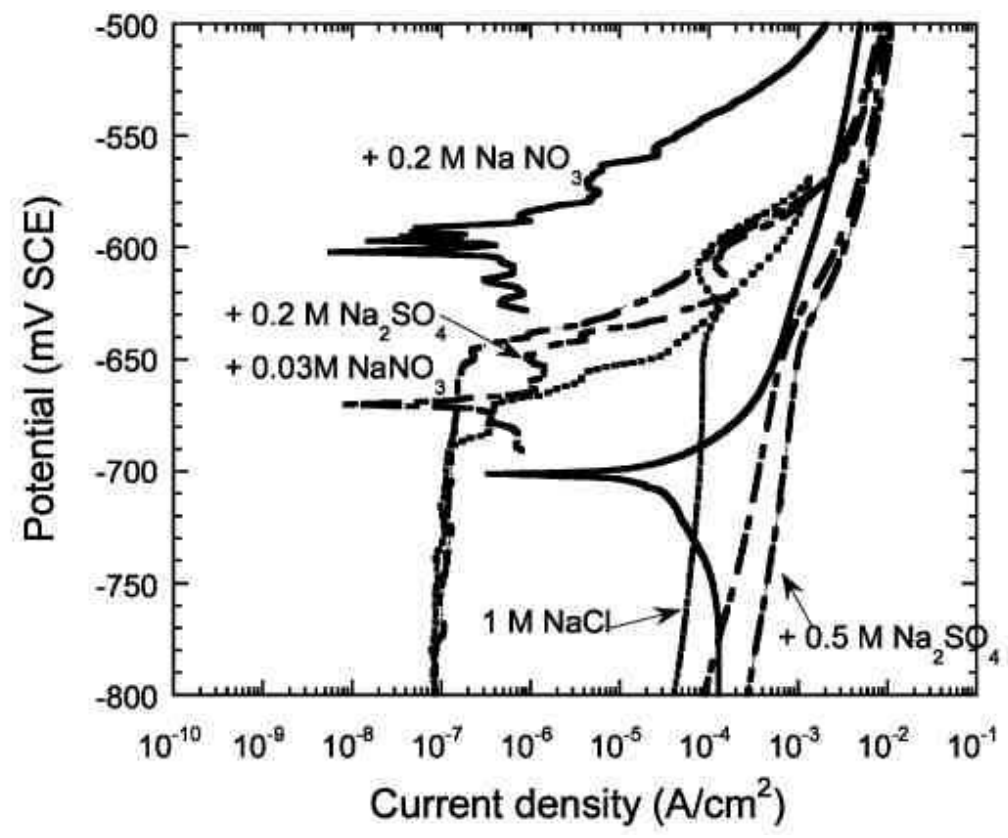

Fig. 25. Cyclic polarization curves for AA2024-T3 in deaerated 1.0 M NaCl with nitrate and sulfate additions.

\section{Summary}

Polarization experiments and metallographic examinations of various tempers of AA2024 were performed, and the following observations were made. 


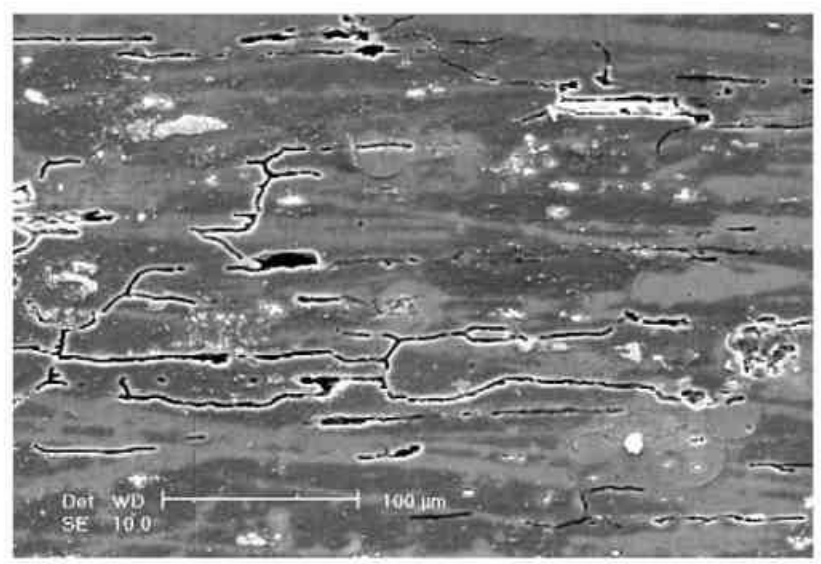

Fig. 26. SEM picture showing IGC of AA2024-T3 (L) potentiostatically polarized at $-580 \mathrm{mV}$ for $20 \mathrm{~h}$ in deaerated $1 \mathrm{M} \mathrm{NaCl}+0.2 \mathrm{M} \mathrm{NaNO}_{3}$.

1) The anodic polarization curves of AA2024 in the solution heat treated and water-quenched condition, T3, and T3+ tempers exhibited two breakdown potentials. The breakdown potentials were found to be independent of sample orientation for any given temper. When two breakdown potentials were observed, the more active one was related to transient dissolution of $\mathrm{S}$ phase intermetallic particle while the noble one was a result of initiation and growth of IGC.

2) Artificial aging had a strong effect on polarization curves and localized corrosion morphology of AA2024. AA2024-T8, T8+, and solutionized and furnace cooled AA2024 exhibited only one breakdown potential. Unlike T3 temper, no sharp IGC was found in the T8 temper. Selected grain attack resulting from breakdown of copper-depleted matrix phase was believed to be the cause for localized corrosion in the T8 and T8+ tempers.

3) A corrosion morphology transition between pitting and intergranular attack was found at critical potentials on the upward or reverse scans in T3 temper. IGC only initiated and grew at high potentials while pitting dominated at low potentials. Like pitting, there may exist an induction period for IGC to initiate. IGC repassivated at a much higher potential than pits.

4) Addition of nitrate to chloride increased the first breakdown potential for $S$ phase dissolution, and changed the repassivation behavior of AA2024-T3. In contrast, sulfate addition appeared to have little influence on the anodic polarization and localized corrosion behavior.

5) TEM observations did not provide much evidence that $\mathrm{Cu}$-depleted zones were present at the grain boundaries of AA2023-T3. However, the $\mathrm{Cu}$-depleted zones were observed in the overaged T8 temper. Artificial aging resulted in more precipitation of intermetallic particles from the matrix and formation of $\mathrm{Cu}$-depleted matrix phase, which greatly changed the localized corrosion of AA2024.

6) AA2024-T3 plate and sheet alloys exhibited different grain structures, but both had similar localized corrosion characteristics.

\section{Acknowledgements}

This work was supported by the United States Air Force Office of Scientific Research through Grant No. F49620-99-1-0103. The authors are grateful to Dr. R. Buchheit for valuable discussion. 


\section{References}

[1] J.R. Galvele, S.M. De Micheli, Corros. Sci. 10 (1970) 795.

[2] I.L. Muller, J.R. Galvele, Corros. Sci. 17 (1977) 179.

[3] M. Posada, L.E. Murr, R.M. Arrowood, Microstruct. Sci. 25 (1997) 131.

[4] G.H. Koch, Corrosion 99, paper No.516, NACE, Houston, TX, 1999.

[5] R.G. Buchheit, J.P. Moran, G.E. Stoner, Corrosion 46 (1990) 610.

[6] K. Orushino, K. Sugimoto, Corros. Sci. 19 (1979) 225.

[7] A. Garner, D. Tromans, Corrosion 35 (1979) 55.

[8] K. Sugimoto, K. Hoshino, M. Kageyama, S. Kageyama, Y. Sawada, Corros. Sci. 15 (1975) 709.

[9] M.J. Robinson, N.C. Jackson, Br. Corros. J. 34 (1999) 45.

[10] M.O. Speidel, M.V. Hyatt, in: M.G. Fontana, R.W. Staehle (Eds.), Advances in Corrosion Science and Technology, vol. 2, Plenum Press, New York, 1972, p. 115.

[11] W. Zhang, G.S. Frankel, J. Electrochem. Soc. 149 (2002) B510.

[12] J.E. Hatch, Al: Properties and Physical Metallurgy, American Society for Metals, Metals Park, OH, 1984.

[13] I.J. Polmer, Light Alloys: Metallurgy of the Light Metals, Wiley, New York, 1996.

[14] D.A. Hardwick, M. Taheri, A.W. Thompson, I.M. Bernstein, Metall. Trans. A 13A (1982) 235.

[15] J.M. Silcock, J. Inst. Met. 89 (1960) 203.

[16] S. Maitra, G.C. English, Mettall. Trans. A 12A (1981) 535.

[17] S. Maitra, G.C. English, Metall. Trans. A 13A (1982) 161.

[18] V. Guillaumin, G. Mankowski, Corros. Sci. 41 (1999) 421.

[19] D.O. Sprowls, R.H. Brown, in: R.W. Staehle, A.J. Forty, D.V. Rooyen (Eds.), Fundamental Aspects of Stress Corrosion Cracking, vols. NACE-1, NACE, Houston,TX, 1967, p. 466.

[20] T. Ramgopal, P. Leblanc, G.S. Frankel, unpublished work.

[21] R.G. Buchheit, R.P. Grant, P.F. Hlava, B. Mckenzie, G.L. Zender, J. Electrochem. Soc. 144 (1997) 2621.

[22] M.O. Speidel, M.V. Hyatt, in: M.G. Fontana, R.W. Staehle (Eds.), Advances in Corrosion Science \& Technology, vol. 2, Plenum Press, New York, NY, 1972, p. 115.

[23] M.E. Inmam, R.G. Kelly, S.A. Willard, R.S. Piascik, Proceedings of the FAA-NACE Symposium on Continued Airworthiness of Aircraft Structures, paper No.9, Atlanta,GA, 1996.

[24] J.R. Galvele, S.M.D. Micheli, I.L. Muller, S.B.D. Wexler, I.L. Alanis, in: R.W. Staehle, B.F. Brown, J. Kruger, A. Agrawal (Eds.), Localized Corrosion, vols. NACE-3, The Electrochemical Society, Pennington, NJ, 1974, p. 580.

[25] H. Bohni, H.H. Uhlig, J. Electrochem. Soc. 116 (1969) 906. 